\title{
Synthesis of Diverse Indole-containing Scaffolds by Gold(I)-Catalyzed Tandem Reactions of 3-Propargylindoles Initiated by 1,2-Indole Migrations: Scope and Computational Studies
}

\author{
Roberto Sanz, ${ }^{*[a]}$ Delia Miguel, ${ }^{[a]}$ Mukut Gohain, ${ }^{[a]}$ Patricia García-García, ${ }^{[a]}$ Manuel A. Fernández \\ Rodríguez, ${ }^{[a]}$ Adán González-Pérez ${ }^{[b]}$ Olalla Nieto-Faza, ${ }^{[b]}$ Ángel R. de Lera, ${ }^{*[b]}$ and Félix \\ Rodríguez $^{*[\mathrm{c}]}$
}

Dedicated with great respect and admiration to our inspiring mentor Prof. Dr. José Barluenga on the occasion of his $70^{\text {th }}$ birthday

\begin{abstract}
Similar to propargylic carboxylates and sulphides, 3propargylindoles undergo 1,2-indole migrations under cationic gold(I)catalysis. The intermediate Aucarbenoid complex may evolve through different pathways depending on the substituents at the propargylic and terminal positions of the alkyne moiety. Thus, 3-indenylindole derivatives were easily obtained through formal iso-
\end{abstract}

Nazarov or Nazarov cyclizations. DFT computations support the formation of an alkylidenecyclopropane intermediate that undergoes aura-iso-Nazarov or aura-Nazarov cyclizations upon torquoselective ring opening. In addition, 3-dienylindoles could be accessed when none of the referred pathways were accessible and so the intermediate $\mathrm{Au}$-carbenoid complex evolved via a 1,2-C-H insertion reaction. We have also demonstrated that the final products can be obtained in a one-pot protocol from easily available propargylic alcohols and indoles.

\section{Keywords: gold • homogeneous catalysis $\bullet$ reaction mechanism $\bullet$ DFT calculations $\bullet$ indoles}

[a] Dr. R. Sanz, Dr. D. Miguel, Dr. M. Gohain, Dr. P. García-García, Dr. M. A. Fernández-Rodríguez

Área de Química Orgánica, Departamento de Química

Facultad de Ciencias, Universidad de Burgos

Pza. Misael Bañuelos s/n, 09001-Burgos (Spain)

Fax: (+34) 947-258831

E-mail: rsd@ubu.es

Homepage:http://www.ubu.es/paginas/grupos_investigacion/cien_biotec/si ntorg/uk/index.

[b] A. González-Pérez, Dr. O. Nieto-Faza, Prof. Dr. A. R. de Lera Departamento de Química Orgánica

Facultad de Química, Universidade de Vigo

Lagoas Marcosende, 36310, Vigo, Galicia (Spain)

Fax: (+34) 986-811940

E-mail: qolera@uvigo.es

[c] Dr. F. Rodríguez

Instituto Universitario de Química Organometálica "Enrique Moles",

Universidad de Oviedo

C/Julián Clavería, 8, 33006, Oviedo (Spain)

E-mail: frodriguez@uniovi.es

Supporting information for this article is available on the WWW under http://www.chemeurj.org/ or from the authors. Full experimental

procedures and characterization data for all the compounds reported in this work, Cartesian coordinates and comprehensive computational analysis are included.

\section{Introduction}

A great number of novel transformations have appeared in last years based on the gold-catalyzed activation of alkynes. ${ }^{[1]}$ In this field, one of the most important processes is the 1,2-acyl migration observed in propargylic esters that generates a metal carbenoid intermediate, as shown in Scheme $1(\mathrm{X}=$ OCOR $){ }^{[2]}$ These goldcarbenoid species can undergo a variety of subsequent transformations. ${ }^{[3]}$ Other heteroatomic nucleophiles, such as a thiogroup, are also able to participate in related 1,2-sulfur migration reactions $(X=S R$, Scheme 1$) .{ }^{[4]}$ In a recent communication we reported the first 1,2-migration reaction of a carbon-centered moiety (in particular a 1,2-indole migration; $X=$ indol-3-yl in Scheme 1). ${ }^{[5]}$

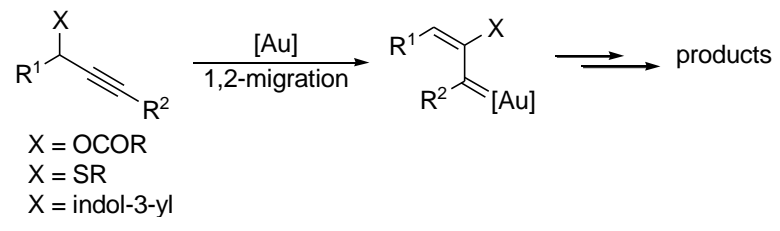

Scheme 1. Gold-catalyzed 1,2-migration reactions.

By contrast to those similar processes described before, our reaction implies the rupture and formation of carbon-carbon bonds instead of rupture and formation of carbon-heteroatom bonds. This idea is 
based on the well established nucleophilic nature of indoles. ${ }^{[6]}$ This characteristic of indoles has already been exploited by several authors to develop some interesting cascade reactions based on the ability of this heterocycle to add to gold-activated alkynes or allenes. ${ }^{[7]}$ Our method was based on the assumption that an indole group at the propargylic position of an alkyne could trigger a 1,2migration reaction similar to that involving propargylic carboxylates or propargylic sulfides. Taking advantage of our reported procedure for the synthesis of C3-propargylated indoles, ${ }^{[8]}$ we were able to easily synthesize a great variety of starting materials and to study the scope of those preliminary reactions. So here, we present a full experimental and theoretical study on this novel 1,2-indole migration reaction including some new reaction pathways.

\section{Results and Discussion}

Preliminary results: We initially studied the rearrangement of the indole derivative 1a as a model system. After a brief screening of different catalysts we realized that complete conversion of the starting material was achieved in less than 30 minutes at room temperature in the presence of catalytic amounts of cationic gold(I) complexes. ${ }^{[9]}$ Thus, 3-(1H-inden-2-yl)- $1 H$-indole derivative 3a was selectively obtained in $79 \%$ yield by using as catalyst the bis(trifluoromethanesulfonyl)imidate derivative $\left[\operatorname{AuNTf}_{2}\left(\mathrm{Ph}_{3} \mathrm{P}\right)\right]$ (Scheme 2, eq. 1). ${ }^{[10]}$ The structure of this new indole derivative 3a was initially established after a series of NMR experiments. An examination of the structure of compound 3a indicates that the phenyl group at the propargylic position has been involved in the rearrangement of 1a and, more important, that a 1,2-indole migration has occurred at some point in the catalytic process.

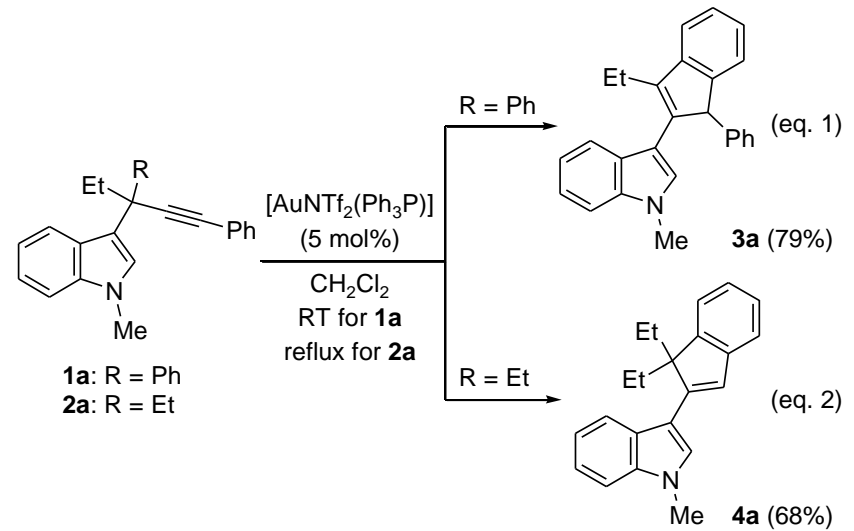

Scheme 2. Gold-catalyzed reaction of C-3-propargylated indoles 1a and 2a.

Surprisingly, when the same reaction was performed with the indole derivative 2a lacking the phenyl-group at the propargylic position (see the presence of two alkyl substituents at the propargylic position) we observed the formation of a new 3-(inden2 -yl)indole $4 \mathbf{a}$ in $68 \%$ yield (Scheme 2, eq. 2). In this case the formation of the indene core involves the reaction of the phenyl group at the terminal position of the starting alkyne. As before, formation of indene derivative 4a can only be explained after an initial 1,2-migration of the indole moiety. The structural assignment of this new compound $\mathbf{4 a}$, initially determined by NMR studies, was confirmed by single-crystal X-ray diffraction analysis. ${ }^{[11]}$ At this point it should be noted that the starting indole derivative 1a possesses a phenyl-group at the propargylic position and another one at the terminal position of the triple bond. Having in mind the results above commented, in principle, both phenyl-groups could be involved in the formation of an indene skeleton. However, in this case only the phenyl-group at the propargylic position participates in the cyclization reaction to give exclusively the indene derivative $\mathbf{3 a}$.

Mechanism of the reactions: As previously stated, formation of compounds 3a and $\mathbf{4 a}$ seems to imply a 1,2-migration of the indole moiety. This suggested to us that the reactions leading to both of these compounds probably proceeded through the formation of a common intermediate obtained after the initial indole migration. Taking this into consideration we believed that the mechanisms depicted in Scheme 3 might account for the formation of compounds 3a and 4a. Thus, an initial coordination of the gold complex to the triple bond of the starting materials 1a or $\mathbf{2 a}$ would take place to form intermediate 5. Intramolecular attack of the indole on the activated alkyne may occur to give the vinyl-gold complex $\mathbf{6}$, which would then become the $\alpha, \beta$-unsaturated gold carbenoid complex 7 through rearrangement and 1,2-migration of the indole nucleus. At this point two reaction pathways are possible depending on the substitution at the $\beta$-carbon of the gold carbenoid intermediate 7 . Thus, when a phenyl group is present at this position (path $a, \mathrm{R}^{1}=$ $\mathrm{Ph}$ ) an intramolecular nucleophilic attack of the phenyl group to the carbene carbon of $\mathbf{7 a}$ would lead to the formation of intermediate $\mathbf{8}$. This transformation (7a to 8) can also be seen as a metalla-isoNazarov process. ${ }^{[12]}$ After formation of $\mathbf{8}$, a rearomatization step and subsequent protodemetalation would render the final product $\mathbf{3 a}$ regenerating the catalytic gold species. The global conversion from 1a to 3a may be considered a tandem sequence involving a 1,2indole migration followed by a formal metalla-iso-Nazarov reaction. For simplicity we will call the pathway leading to the indene derivative 3a the aura-iso-Nazarov mechanism (path $a$ in Scheme 3).

On the other hand, when the starting indole derivative bears two alkyl groups at the propargylic positions (path $b, \mathrm{R}^{1}=\mathrm{R}^{2}=\mathrm{Et}$ ), the carbene intermediate $\mathbf{7 b}$ may evolve through a Nazarov-type cyclization to give 9. ${ }^{[13]}$ Alternatively, an intramolecular capture of the gold-stabilized allyl cation by the phenyl group could also be considered to explain this step. ${ }^{[13 \mathrm{~d}, 14]}$ Ultimately, after a rearomatization and protodemetalation, product $\mathbf{4 a}$ would be formed For simplicity, we will call the pathway leading to indene derivative 4a the aura-Nazarov mechanism (path $b$ in Scheme 3). 


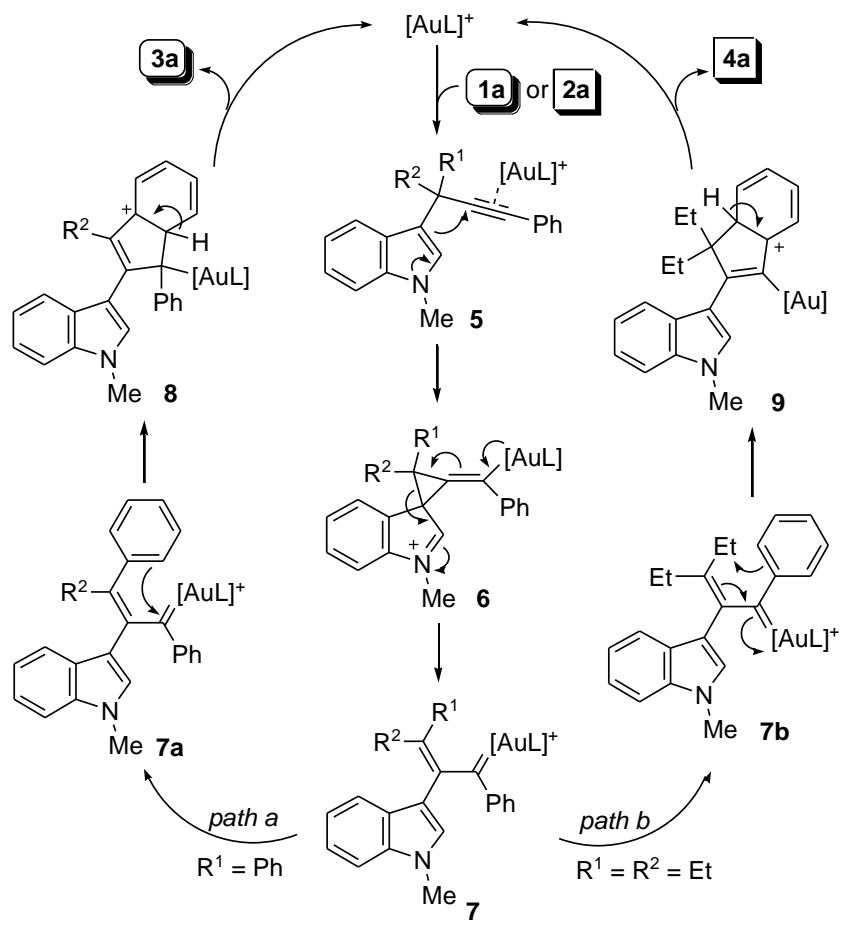

Scheme 3. Proposed mechanism for the formation of $\mathbf{3 a}$ and $\mathbf{4 a}$.

Theoretical studies: We sought to provide computational support to the proposed mechanism for this unprecedented 1,2-indole migration upon gold activation of the alkyne in the starting C3propargylated indoles, in particular concerning the feasibility of the alkylidenecyclopropane intermediate and its further evolution to a gold carbocation/carbenoid. The analysis of the transition structure for the ensuing cyclization from the gold species could help to determine whether a Nazarov-type or other alternative mechanisms are operating. ${ }^{[15]}$ With the computational exploration of the mechanistic alternatives for these transformations we aimed to establish the factors governing the switch in product distribution and also shed light on the specific role of the gold centre and the indole heterocycle, an uncommon nucleophile for this kind of rearrangement of propargylic substrates. For the calculations, we have chosen model systems $\mathbf{V a}$ and $\mathbf{V b}$ (Figure 1, the Roman numerals corresponding to model structures of Scheme 3 will be used throughout for clarity), with and without a propargylic phenyl group, respectively, as a compromise structure between the two simplest models reported. Also for the sake of simplicity and reduced computational cost, gold's ligand was chosen to be $\mathrm{PH}_{3}$.

Computational details: Stationary points along the $\mathbf{V}$ to $\mathbf{I X}$ transformation for the two reacting systems have been located using DFT in its Kohn-Sham approach, with the B3LYP ${ }^{[16]}$ and M06 functionals, ${ }^{[17]}$ and a $6-31 \mathrm{G}(\mathrm{d})$ basis set ${ }^{[18]}$ for the main group atoms and the LANL2DZ electron core potential ${ }^{[19]}$ and associated basis set for gold. Geometry optimization and harmonic analysis of the frequencies was carried out at both DFT hybrid functional levels of theory. Solvation effects were taken into consideration when computing the reaction profiles of Figure 1. The polarizable continuum model $(\mathrm{PCM})^{[20]}$ was employed with dichloromethane parameters in a single point energy calculation and the molecular cavity created with the UAKS radii set. The results, qualitatively similar to those obtained in gas phase, are listed in the Supporting Information. All calculations have been performed with the Gaussian09 program suite. ${ }^{[21]}$ The calculations with the hybrid meta exchange correlation functional M06, which has shown good performance for the study of transition metal-catalyzed reactions, ${ }^{[17]}$ provide a comparison with the B3LYP functional (the M06 values are shown on Figure 1 and listed in Table 1). In general, the activation barriers are higher with M06, except for the iso-Nazarov reaction (vide infra), whereas the minima are less stabilized, which allowed to locate intermediate VIa. Since the interpretation of the reaction mechanism is similar using both functionals, only the B3LYP values will be used along the discussion.

Theoretical results: The results of our computational study are summarized in Figure 1 and the relative and activation free energies for the proposed paths are collected in Table 1. Gold coordination to the alkyne in the first step can take place either anti or syn to the indole heterocycle, which generates two families of isomers for each system. Only the pathways that start from the anti coordination of gold and lead to the $E$ olefin in VI will be discussed. ${ }^{[22]}$ Although energy differences are not significant for the minima in these alternate paths, the equivalent mechanisms starting from syn coordination (see Supporting Information) and providing a $Z$ goldsubstituted olefin are globally higher in energy (about $5 \mathrm{kcal} \mathrm{mol}^{-1}$ for the first transition states).

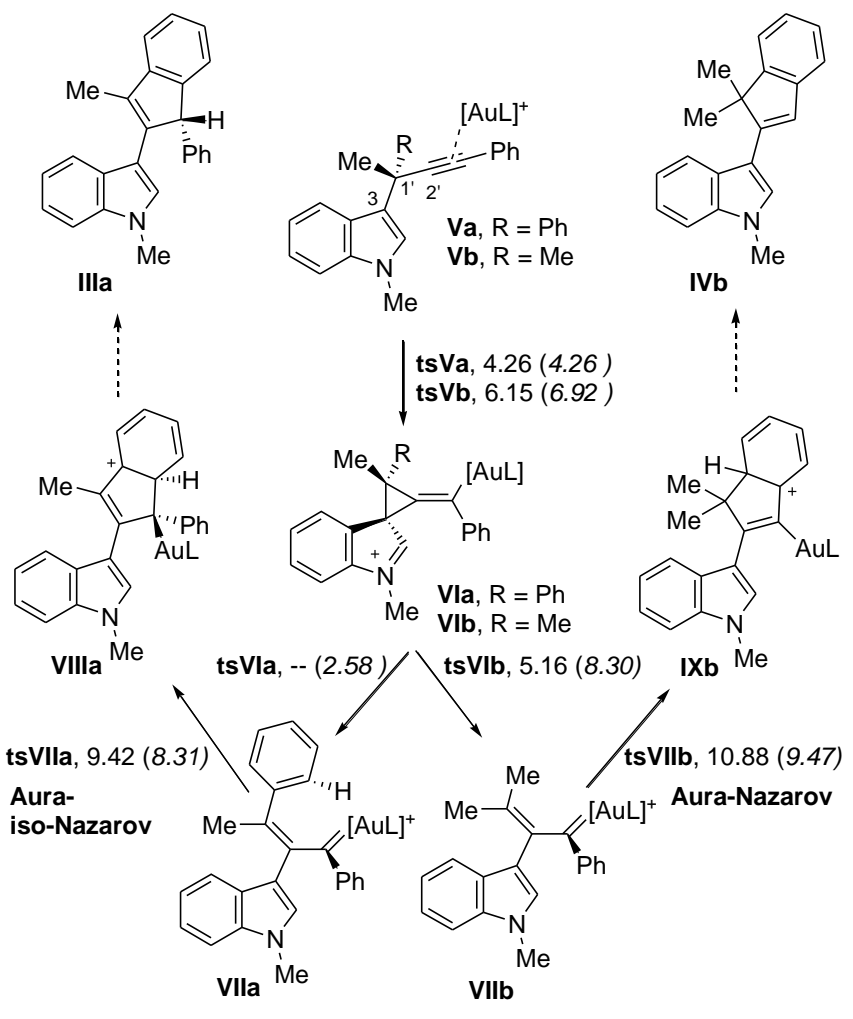

Figure 1. General mechanistic proposal for the gold-mediated rearrangement of 3 propargylindoles with different substituents $(\mathrm{Me}, \mathrm{Ph})$ at the internal propargylic position (one of the enantiomers of Va was arbitrarily chosen). The free energy values (relative to starting complexes $\mathbf{V a}$ and $\mathbf{V b}$ ) are given in $\mathrm{kcal} \mathrm{mol}^{-1}$. All computations have been carried out at the B3LYP/6-31G(d) level and the M06/6-31G(d) level (values in brackets).

Starting from $\mathbf{V}$, the first step involves a capture at $\mathbf{C} 2$ ' of the gold-activated alkyne by nucleophilic attack of the indole $\mathrm{C} 3$ position, resulting in the formation of a new $\mathrm{C}-\mathrm{C}$ bond through an early transition state (see Figure 2). The fate of the system after this low-energy transition state $\left(4.26 \mathrm{kcal} \mathrm{mol}^{-1}\right.$ for tsVa and $6.15 \mathrm{kcal}$ $\mathrm{mol}^{-1}$ for tsVb) however, depends on the substitution pattern at the propargylic position. The system with alkyl substituents evolves to 
an alkylidenecyclopropane intermediate VIb. Worthy of note, whereas the $\mathrm{C} 1$ ' $-\mathrm{C} 2$ ' bond is longer $(1.58 \AA)$ and the formed C3-C2' is shorter (1.49 $\AA$ ) than those of cyclopropane (1.51 $\AA$ ), the $\mathrm{C} 3-\mathrm{C} 1$ ' bond is elongated to $1.62 \AA{ }^{[23]}$ favouring the ensuing rearrangement with $\mathrm{C} 3-\mathrm{C} 1$ ' scission. Intermediate $\mathbf{V I b}$ is then connected to the "aura-carbenoid" [24] VIIb through tsVIb, in the rate-limiting step of the tandem rearrangement. In this transition state the alkylidene group on the cyclopropane ring smoothly rotates to minimize the steric interaction between the phenyl and the indole rings in VIIb.

Table 1. Relative and activation free energies (in $\mathrm{kcal} \mathrm{mol}^{-1}$ ) for the stationary points of the mechanisms depicted in Figure 1 in gas phase. ${ }^{[a]}$

\begin{tabular}{llllll}
\hline & $\Delta \mathrm{G}_{\text {rel }}$ & $\Delta \mathrm{G}^{\#}$ & & $\Delta \mathrm{G}_{\text {rel }}$ & $\Delta \mathrm{G}^{\#}$ \\
\hline Va & 0.00 & & Vb & 0.00 & \\
tsVa & 4.26 & 4.26 & tsVb & 6.15 & 6.15 \\
& $(4.26)$ & $(4.26)$ & & $(6.92)$ & $(6.92)$ \\
Vla & $--^{[b]}$ & & VIb & 5.33 & \\
& $(1.62)$ & & & $(6.51)$ & \\
tsVla & $--\left[{ }^{[b]}\right.$ & $-{ }^{[b]}$ & tsVIb & 10.49 & 5.16 \\
& $(4.20)$ & $(2.58)$ & & $(14.81)$ & $(8.30)$ \\
VIIa & -9.65 & & VIIb & -5.47 & \\
& $(-8.22)$ & & & $(-1.74)$ & \\
tsVIIa & -0.23 & 9.42 & tsVIIb & 5.42 & 10.88 \\
& $(0.08)$ & $(8.31)$ & & $(7.74)$ & $(9.47)$ \\
VIIIa & -12.08 & & IXb & -7.89 & \\
& $(-17.44)$ & & & $(-8.87)$ & \\
\hline
\end{tabular}

[a] All computations have been carried out at the B3LYP/6-31G(d) and the M06/6$31 \mathrm{G}(\mathrm{d})$ level (values in brackets). [b] The missing values (denoted as ---) correspond to the B3LYP barrierless process tsVa to VIIa illustrated in the Supporting Information (Figure S1). The free energy values in dichloromethane solution (PCM) can be found in the Supporting Information.

This picture is somewhat modified for the analog system with a phenyl group at $\mathrm{C} 1$ '. The spirocycle VIa and the corresponding ring-opening transition state tsVIa, which would connect it to VIIa, could only be located as stationary points on the potential energy surface corresponding to Va using the M06 functional. ${ }^{[25]}$
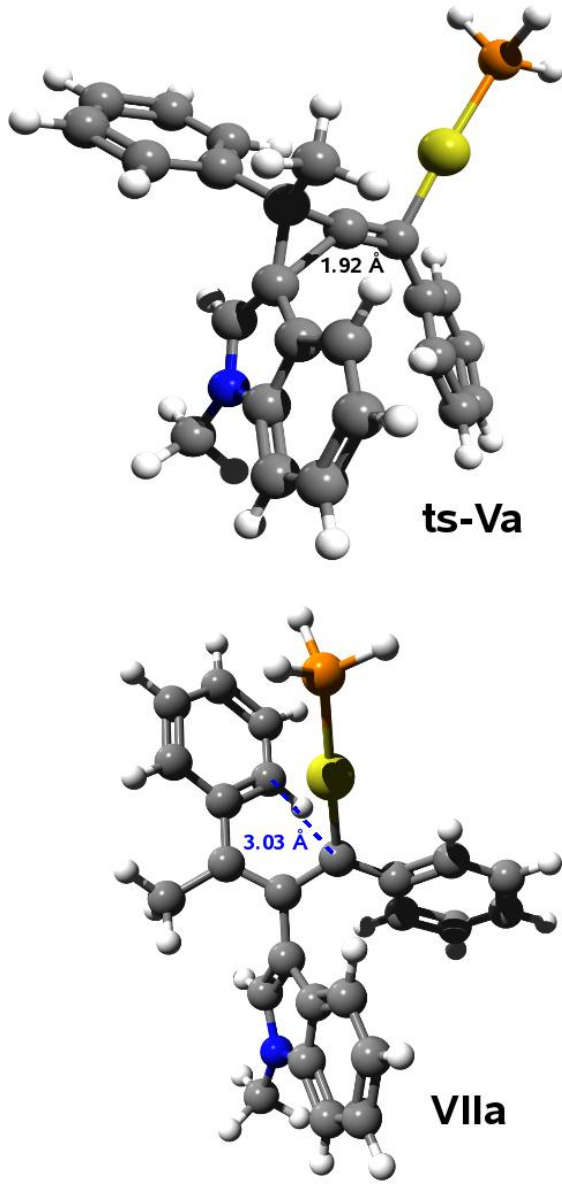

Figure 2. Gas phase computed (B3LYP/6-31G(d)) geometries of TSVa and VIIa

Thus, both mechanisms converge in structures VII, formally cationic gold species within conjugated pentadienyl systems. For the phenyl-substituted propargylic system we find that the VIa to VIIa process is also torquoselective and affords intermediate VIIa (Figure 2) with $Z$ geometry of the olefin due to the minimization of the steric interactions of the indole and rotating phenyl groups upon cyclopropane ring opening. The evolution of VIIlb to VIIIb via a gold-stabilized pentadienyl cation cyclization (aura-Nazarov process $)^{[13,15 \mathrm{e}-\mathrm{g}]}$ is expected, given the proximity of the $\mathrm{C} 1$ ' $-\mathrm{C} 2$ ' olefin and the terminal phenyl group in the conformation adopted by VIb after the indole migration is complete. As explained, following the ring opening of VIb, the developing allylic strain between the terminal $\mathrm{Ph}$ and the indole heterocycle results in the rotation of the $\mathrm{C} 1$ ' $-\mathrm{C} 2$ ' $-\mathrm{C} 3$ ' $-\mathrm{Ph}$ dihedral being coupled with the ring opening in VIb and affording an helical structure VIIb ( $P$ from the configuration of $\mathbf{V b}$ shown in Figure 1). Thus, the following VIIb to IXb concerted electrocyclization benefits from the already enforced helical conformation resulting in a $10.88 \mathrm{kcal} \mathrm{mol}^{-1}$ reaction barrier.

The aromaticity of the transition structures has often been utilized for the characterization of pericyclic molecular rearrangements. A useful magnitude to estimate the aromaticity is the nucleus-independent chemical shift $(\mathrm{NICS})^{[27]}$ with large negative NICS values corresponding to diatropic ring currents related to aromaticity ( -9.7 for benzene at the ring centre) and positive values associated to paratropic ring currents and antiaromaticity. The NICS at the ring center of tsVIIb $(-10.4 \mathrm{ppm})$ confirms its aromatic character and therefore the rearrangement can be considered as a $4 \pi \mathrm{e}^{-}$-electrocyclic process. 
The evolution of VIIa would take place by electrocyclic ring closure involving the phenyl ring cis to the gold-containing carbon atom. In this alternative aura-iso-Nazarov ${ }^{[12]}$ reaction the goldstabilized cation is located at the terminus of the cyclizing system. The initial selectivity of the $\pi$ gold alkyne coordination (anti to the indole) leads to a $Z$ double bond (the bulky phenyl group on $\mathrm{C1}$ ' tends to rotate outwards in the 4-electron ring opening of VIa, away from the indole, in order to reduce the steric strain in VIIa) and to an s-trans conformation of the adjacent bond. This directly results in a helical pentadienyl cation structure poised to undergo an electrocyclic ring closure. ${ }^{[15]}$

The computed energy values for these transition states confirm that the aura-iso-Nazarov is favoured over the alternative auraNazarov reaction channel available from the twisted s-cis conformation of VIIa (see Figure 2 and Supporting Information). The energy barrier for the favoured cyclization of VIIa, $9.42 \mathrm{kcal}$ $\mathrm{mol}^{-1}$ is $2.29 \mathrm{kcal} \mathrm{mol}^{-1}$ lower than the alternative ring-closure that would involve the external $\mathrm{Ph}$ group (11.71 kcal mol${ }^{-1}$ ). Moreover, it is $3.67 \mathrm{kcal} \mathrm{mol}^{-1}$ more favourable than yet another aura-isoNazarov reaction available from the initial syn coordination of gold to the alkyne (Supporting Information). ${ }^{[28]}$ The preference for the cyclization leading to VIIIa is also reinforced by the expected high barrier of bond rotation to the proper s-cis conformation required by the pentadienyl cation extended to the terminal phenyl group. The calculated NICS ${ }^{[27]}$ at the ring center of tsVIIa with a value of -9.2 $\mathrm{ppm}$, indicates likewise the electrocyclic nature of the process.

A last step from VIIIa and IXb, which already exhibit the main structural motif of the products, to IIIa and IVb is required to recover the aromaticity of the systems. Proton abstraction on VIIIa and IXb can be mediated by a soft base resulting in the weakening of the $\mathrm{Au}-\mathrm{C}$ bond and formation of the final indenylindole derivative. The gold catalyst can then be released again to the solution and reincorporated into the catalytic cycle.

To summarize this section, our computational studies confirm the anticipated overall mechanistic picture, comprising three major steps: a) the electrophilic addition of the gold-activated alkyne to the indole ring with formation of the alkylidenecyclopropane intermediate, b) its further evolution by indole-induced torquoselective $4 \pi \mathrm{e}^{-}$-electrocyclic ring opening to a gold carbocation/carbenoid, and c) the $4 \pi \mathrm{e}^{-}$-electrocyclic ring closure of the gold-stabilized carbocation species in processes that can be considered as gold variants of the Nazarov or iso-Nazarov reactions. The analysis of the aromaticity of the transition structures for the cyclization is consistent with the consideration of the processes as pericyclic reactions. Whereas the systems with dialkyl groups at the propargylic position follow the Nazarov manifold, the presence of an aryl group at this position induces a shift in the mechanism, which now follows the iso-Nazarov pathway in preference over the alternative Nazarov, thus explaining the product distribution with otherwise similar substrates. The lower activation energy for the rate-limiting aura-iso-Nazarov reaction relative to the aura-Nazarov explains the higher temperatures required for the rearrangement of the propargylic substrates substituted with dialkylgroups 2 vis-a-vis the alkyl-aryl analogue $\mathbf{1}$.

Scope of the gold-catalyzed tandem reactions: After having established the mechanisms and conditions for the transformation of C3-propargylated indoles $\mathbf{1 a}$ and $\mathbf{2 a}$ to 3-(inden-2-yl)indole derivatives $\mathbf{3 a}$ and $\mathbf{4 a}$, the scope and limitations of these novel catalytic tandem processes have been explored. Most of the reactions were performed in the presence of $\left[\operatorname{AuNTf}_{2}\left(\mathrm{Ph}_{3} \mathrm{P}\right)\right]$ that was the catalyst of choice due to its availability and ease of handling.

Synthesis of 3-(1H-inden-2-yl)- $1 H$-indoles 3 by tandem $1,2-$ indole migration/aura-iso-Nazarov reaction: Reaction of a series of indole derivatives $\mathbf{1}$ possessing both an aromatic and an aliphatic substituent at the propargylic positions and either aromatic or aliphatic groups at the alkyne terminus were conducted under the optimized conditions. The results are summarized in Table 2. These data show that the process is efficient with alkynes 1 having indolegroups with a wide range of substitution patterns. Thus, substrates bearing $N$-methylindole (Table 2, entries 1-5), indole (Table 2, entries 6-7), 2-methylindole (Table 2, entry 11), 1,2-dimethylindole (Table 2, entries 12-14) as well as 1-methyl-2-phenylindole and 1,2-diphenylindole (Table 2, entries 15-17) efficiently furnished the indenyl adducts $\mathbf{3}$. Interestingly, starting materials $\mathbf{1 h}-\mathbf{j}$ containing less nucleophilic indole moieties (those with electron-withdrawing substituents at C-5 of the indole ring) also underwent the migration/iso-Nazarov tandem sequence to finally afford the corresponding indenes $\mathbf{3 h} \mathbf{- j}$ in good yields (Table 2, entries 8-10). Moreover, various aromatic and linear or branched aliphatic substituents were also well tolerated at both the propargylic $\left(\mathrm{R}^{4}\right.$ in scheme of Table 2) and the terminal position of the triple bond $\left(\mathrm{R}^{5}\right.$ in scheme of Table 2). The isomerization of indole derivatives $\mathbf{1 r - u}$ having a terminal alkyne moiety was also investigated (Table 2, entries 18-21). Reactions of these substrates in the presence of catalytic amounts of $\left[\mathrm{AuNTf}_{2}\left(\mathrm{Ph}_{3} \mathrm{P}\right)\right]$ under the optimized conditions followed the same reaction pathway previously observed for internal alkynes to furnish the observed compounds 3r-u. However, it should be noted that in accordance with the observations of other authors ${ }^{[4]}$ in these cases the reaction initially furnishes a mixture of two regioisomeric indenes which could be converted into the desired indene derivatives $3 \mathbf{r}-\mathbf{u}$ by simple treatment of the crude of the reaction with $5 \mathrm{~mol} \%$ of $p$-toluenesulfonic acid. Interestingly, functionalized alkynes $\mathbf{1 v}$ and $\mathbf{1 w},{ }^{[29]}$ bearing a phenylthio- and an ester-group respectively at the triple bond, also gave the expected indene derivatives $\mathbf{3 v} \mathbf{- w}$ in high yield (Table 2, entries 22 and 23). Moreover, reaction of starting material $\mathbf{1 x}$, which contains a free alcohol in the alkyl chain of the substituent at the triple bond, occurred in the same fashion to give the indenyl adduct $\mathbf{3 x}$ in high yield (Table 2, entry 24). It should be noted that in this particular case we did not observe the formation of products coming from an also possible 5-endo-hydroalkoxylation reaction of the carbon-carbon triple bond. ${ }^{[30]}$ Structural assignments of all new compounds were based on a series of NMR studies or established by analogy. Additionally, the structures of $\mathbf{3 c}$ and $\mathbf{3 e}$ were confirmed by single-crystal X-ray diffraction analysis. ${ }^{[11]}$

Table 2. Preparation of 3-(1H-inden-2-yl)- $1 H$-indoles 3 by gold-catalyzed tandem 1,2indole migration/iso-Nazarov reactions of $\mathrm{C} 3$-propargylated indole derivatives $1{ }^{\text {[a] }}$

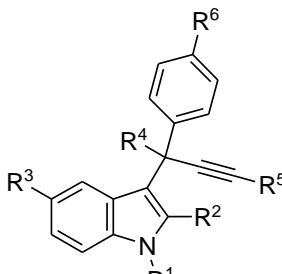

$1 \stackrel{\mathrm{R}}{1}$

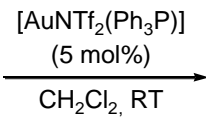

$\mathrm{CH}_{2} \mathrm{Cl}_{2} \mathrm{RT}$

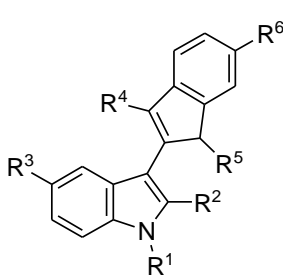

3

\begin{tabular}{llllllllll}
\hline Entry & $\mathbf{1}$ & $\mathrm{R}^{1}$ & $\mathrm{R}^{2}$ & $\mathrm{R}^{3}$ & $\mathrm{R}^{4}$ & $\mathrm{R}^{5}$ & $\mathrm{R}^{6}$ & $\mathbf{3}$ & $\begin{array}{c}\text { Yield } \\
{[\%]^{[\mathrm{b}]}}\end{array}$ \\
\hline 1 & $\mathbf{1 a}$ & $\mathrm{Me}$ & $\mathrm{H}$ & $\mathrm{H}$ & $\mathrm{Et}$ & $\mathrm{Ph}$ & $\mathrm{H}$ & $\mathbf{3 a}$ & 79
\end{tabular}




\begin{tabular}{|c|c|c|c|c|c|c|c|c|c|}
\hline & $1 \mathrm{~b}$ & Me & $\mathrm{H}$ & $\mathrm{H}$ & $n \mathrm{Pr}$ & $\mathrm{Ph}$ & $\mathrm{H}$ & $3 b$ & 75 \\
\hline 3 & 1c & $\mathrm{Me}$ & $\mathrm{H}$ & $\mathrm{H}$ & $\mathrm{iPr}$ & $\mathrm{Ph}$ & $\mathrm{H}$ & $3 c$ & 76 \\
\hline 4 & 1d & $\mathrm{Me}$ & $\mathrm{H}$ & $\mathrm{H}$ & $\mathrm{iPr}$ & $n \mathrm{Bu}$ & $\mathrm{H}$ & $3 d$ & 73 \\
\hline 5 & $1 e$ & $\mathrm{Me}$ & $\mathrm{H}$ & $\mathrm{H}$ & $\mathrm{Me}$ & $n \mathrm{Bu}$ & $\mathrm{Cl}$ & $3 e$ & $79^{[c]}$ \\
\hline 6 & $1 f$ & $\mathrm{H}$ & $\mathrm{H}$ & $\mathrm{H}$ & $n \mathrm{Pr}$ & $\mathrm{Ph}$ & $\mathrm{H}$ & $3 f$ & 60 \\
\hline 7 & $1 \mathrm{~g}$ & $\mathrm{H}$ & $\mathrm{H}$ & $\mathrm{H}$ & $\mathrm{Me}$ & $n \mathrm{Bu}$ & $\mathrm{H}$ & $3 g$ & 66 \\
\hline 8 & $1 \mathrm{~h}$ & $\mathrm{H}$ & $\mathrm{H}$ & $\mathrm{CO}_{2} \mathrm{Me}$ & $\mathrm{Me}$ & $n \mathrm{Bu}$ & $\mathrm{H}$ & $3 h$ & 75 \\
\hline 9 & $1 \mathrm{i}$ & $\mathrm{H}$ & $\mathrm{H}$ & $\mathrm{CO}_{2} \mathrm{Me}$ & $\mathrm{Et}$ & $n \mathrm{Bu}$ & $\mathrm{H}$ & $3 \mathbf{i}$ & 70 \\
\hline 10 & $1 \mathrm{j}$ & $\mathrm{H}$ & $\mathrm{H}$ & $\mathrm{Br}$ & $\mathrm{Me}$ & $n \mathrm{Bu}$ & $\mathrm{H}$ & $3 \mathbf{j}$ & 69 \\
\hline 11 & $1 \mathrm{k}$ & $\mathrm{H}$ & $\mathrm{Me}$ & $\mathrm{H}$ & $\mathrm{Me}$ & $\mathrm{Ph}$ & $\mathrm{H}$ & $3 k$ & 68 \\
\hline 12 & 11 & $\mathrm{Me}$ & $\mathrm{Me}$ & $\mathrm{H}$ & $\mathrm{Me}$ & $\mathrm{Ph}$ & $\mathrm{H}$ & 31 & $68^{[c]}$ \\
\hline 13 & $1 \mathrm{~m}$ & $\mathrm{Me}$ & $\mathrm{Me}$ & $\mathrm{H}$ & $\mathrm{Et}$ & $\mathrm{Ph}$ & $\mathrm{H}$ & $3 m$ & 70 \\
\hline 14 & $1 n$ & $\mathrm{Me}$ & $\mathrm{Me}$ & $\mathrm{H}$ & $n \mathrm{Pr}$ & $n \mathrm{Bu}$ & $\mathrm{H}$ & $3 n$ & 67 \\
\hline 15 & 10 & $\mathrm{Me}$ & $\mathrm{Ph}$ & $\mathrm{H}$ & $\mathrm{Me}$ & $\mathrm{Ph}$ & $\mathrm{H}$ & 30 & $73^{[\mathrm{d}]}$ \\
\hline 16 & $1 p$ & $\mathrm{Me}$ & $\mathrm{Ph}$ & $\mathrm{H}$ & Et & $\mathrm{Ph}$ & $\mathrm{H}$ & $3 p$ & 78 \\
\hline 17 & $1 q$ & $\mathrm{Ph}$ & $\mathrm{Ph}$ & $\mathrm{H}$ & $c \mathrm{C}_{6} \mathrm{H}_{11}$ & $\mathrm{Ph}$ & $\mathrm{H}$ & $3 q$ & 86 \\
\hline $18^{[e]}$ & $1 r$ & $\mathrm{Me}$ & $\mathrm{H}$ & $\mathrm{H}$ & $c \mathrm{C}_{3} \mathrm{H}_{5}$ & $\mathrm{H}$ & $\mathrm{H}$ & $3 r$ & 83 \\
\hline $19^{[\mathrm{e}]}$ & $1 \mathrm{~s}$ & $\mathrm{H}$ & $\mathrm{Ph}$ & $\mathrm{H}$ & Et & $\mathrm{H}$ & $\mathrm{H}$ & $3 s$ & 71 \\
\hline $20^{[e]}$ & $1 t$ & $\mathrm{H}$ & $\mathrm{Ph}$ & $\mathrm{H}$ & Et & $\mathrm{H}$ & $\mathrm{Cl}$ & $3 t$ & 70 \\
\hline $21^{[\mathrm{e}]}$ & $1 u$ & $\mathrm{H}$ & $\mathrm{Ph}$ & $\mathrm{H}$ & $c \mathrm{C}_{3} \mathrm{H}_{5}$ & $\mathrm{H}$ & $\mathrm{H}$ & $3 u$ & 84 \\
\hline 22 & $1 v$ & $\mathrm{Me}$ & $\mathrm{H}$ & $\mathrm{H}$ & $c \mathrm{C}_{3} \mathrm{H}_{5}$ & $\mathrm{SPh}$ & $\mathrm{H}$ & $3 v$ & 84 \\
\hline 23 & $1 w$ & $\mathrm{Me}$ & $\mathrm{H}$ & $\mathrm{H}$ & $c \mathrm{C}_{3} \mathrm{H}_{5}$ & $\mathrm{CO}_{2} \mathrm{Et}$ & $\mathrm{H}$ & $3 w$ & 75 \\
\hline 24 & $1 x$ & $\mathrm{Me}$ & $\mathrm{H}$ & $\mathrm{H}$ & $c \mathrm{C}_{3} \mathrm{H}_{5}$ & $\left(\mathrm{CH}_{2}\right)_{2} \mathrm{OH}$ & $\mathrm{H}$ & $3 x$ & 76 \\
\hline
\end{tabular}

[a] Reactions stirred at room temperature till consumption of the starting material $(0.5-7 \mathrm{~h})$, as judged by GC-MS analysis. [b] Yield of isolated product based on the corresponding starting indole 1. [c] Reaction performed with $\left[\mathrm{AuCl}\left(\mathrm{Ph}_{3} \mathrm{P}\right)\right] / \mathrm{AgSbF}_{6}$ as catalyst. [d] Reaction performed with $\left[\mathrm{AuNTf}_{2}(\mathrm{SPhos})\right]$ as catalyst $(\mathrm{SPhos}=2$ dicyclohexylphosphino-2',6'-dimethoxybiphenyl). [e] The crude reaction mixture was treated with PTSA (5 mol\%) in acetonitrile at reflux after the complete consumption of the corresponding starting indole $\mathbf{1}$.

To test the capability of heteroaromatic substituents to partake in the iso-Nazarov cyclization of the tandem process we turned our attention to the rearrangement of compounds $\mathbf{1 0 a}-\mathbf{b}$ possessing a thiophene group at the propargylic position. Pleasantly, reactions of these substrates under the optimized conditions occurred in high yields to provide exclusively the corresponding 5indolylcyclopenta[ $b]$ thiophene derivatives 11a-b (Scheme 4). Moreover, these experiments demonstrate that the method here described is appropriate not only for the synthesis of indene derivatives but also for the synthesis of other fused-bicyclic compounds.

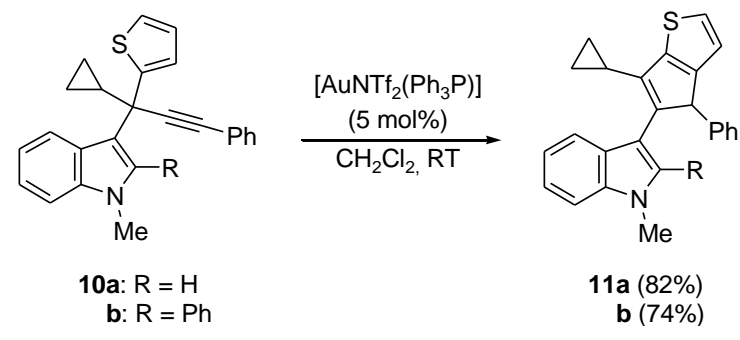

Scheme 4. Gold-catalyzed tandem 1,2-indole migration/iso-Nazarov reactions of indole derivatives 10a-b.

Synthesis of 3-(inden-2-yl)indoles 4 by tandem 1,2-indole migration/aura-Nazarov reaction: Having studied the scope of the gold-catalyzed isomerization reactions of substrates $\mathbf{1}$, we turned our attention to the tandem 1,2-indole migration/Nazarov cyclization process. The reaction of a series of representative alkynes $\mathbf{2}$, having all of them a phenyl group at the alkyne terminus and two aliphatic substituents at the propargylic position, was conducted to evaluate the scope of this transformation (Table 3). The results revealed that the tandem process occurs with several C3-propargylated indoles 2 bearing indole moieties such as $N$-methylindole (Table 3 , entries 1-3), indole (Table 3, entry 4), 2-methylindole (Table 3, entry 5), 2phenylindole (Table 3, entry 6) and 1,2-dimethylindole (Table 3, entries 7-8). Moreover, both linear and branched aliphatic substituents were also well tolerated at the propargylic carbon $\left(\mathrm{R}^{3}\right.$ and $\mathrm{R}^{4}$ in scheme of Table 3). Structural assignments of all cycloadducts 4 were based on a series of NMR experiments. Additionally, the structure of $\mathbf{4 b}$ was confirmed by single-crystal Xray diffraction analysis. ${ }^{[1]}$

Table 3. Preparation of 3-(inden-2-yl)indoles 4 by gold-catalyzed tandem 1,2-indole migration/Nazarov-type cyclization of C3-propargylated indole derivatives 2 . ${ }^{\text {[a] }}$
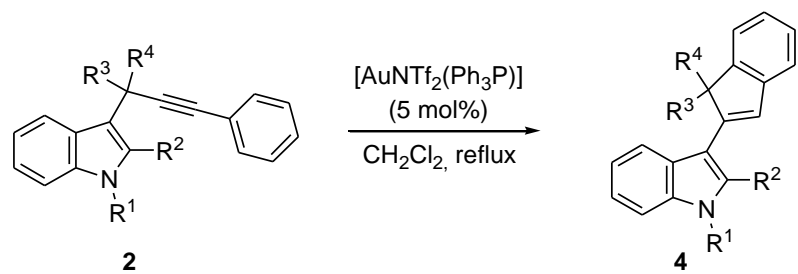

\begin{tabular}{llllllll}
\hline Entry & $\mathbf{2}$ & $\mathrm{R}^{1}$ & $\mathrm{R}^{2}$ & $\mathrm{R}^{3}$ & $\mathrm{R}^{4}$ & $\mathbf{4}$ & $\begin{array}{l}\text { Yield } \\
{[\%]^{[b]}}\end{array}$ \\
\hline 1 & $\mathbf{2 a}$ & $\mathrm{Me}$ & $\mathrm{H}$ & $\mathrm{Et}$ & $\mathrm{Et}$ & $\mathbf{4 a}$ & 68 \\
2 & $\mathbf{2 b}$ & $\mathrm{Me}$ & $\mathrm{H}$ & $\mathrm{Me}$ & $\mathrm{Me}$ & $\mathbf{4 b}$ & 82 \\
3 & $\mathbf{2 c}$ & $\mathrm{Me}$ & $\mathrm{H}$ & $\mathrm{Me}$ & $c \mathrm{C}_{3} \mathrm{H}_{5}$ & $\mathbf{4 c}$ & 87 \\
4 & $\mathbf{2 d}$ & $\mathrm{H}$ & $\mathrm{H}$ & $\mathrm{Me}$ & $c \mathrm{C}_{3} \mathrm{H}_{5}$ & $\mathbf{4 d}$ & 75 \\
5 & $\mathbf{2 e}$ & $\mathrm{H}$ & $\mathrm{Me}$ & $\mathrm{Me}$ & $c \mathrm{C}_{3} \mathrm{H}_{5}$ & $\mathbf{4 e}$ & 80 \\
6 & $\mathbf{2 f}$ & $\mathrm{H}$ & $\mathrm{Ph}$ & $c \mathrm{C}_{3} \mathrm{H}_{5}$ & $c \mathrm{C}_{3} \mathrm{H}_{5}$ & $\mathbf{4 f}$ & 77 \\
7 & $\mathbf{2 g}$ & $\mathrm{Me}$ & $\mathrm{Me}$ & $\mathrm{Me}$ & $\mathrm{Me}$ & $\mathbf{4 g}$ & 72 \\
8 & $\mathbf{2 h}$ & $\mathrm{Me}$ & $\mathrm{Me}$ & $\mathrm{Me}$ & $c \mathrm{C}_{3} \mathrm{H}_{5}$ & $\mathbf{4 h}$ & 81 \\
\hline
\end{tabular}

[a] Reactions stirred at reflux till consumption of the starting material (1-24 h), as judged by GC-MS analysis. [b] Yield of isolated product based on the corresponding starting indole 2 .

To further test the scope of the process we explored the reaction with starting materials where the substituent at the terminal position of the alkyne was different from a simple phenyl-group. We were pleased to find that indole derivatives 12a-b, bearing a 3-thienyl group at the alkyne terminus, afforded the corresponding 5indolylcyclopenta $[b]$ thiophene derivatives $\mathbf{1 3 a}-\mathbf{b}$ in high yields (Scheme 5, eq. 1). The structure of compound $\mathbf{1 3 b}$ and so, the regioselectivity of the cyclization regarding the thiophene ring, was confirmed by single-crystal X-ray diffraction analysis. ${ }^{[11]}$ Not only heteroaromatic groups but also simple olefins can partake in the tandem process as demonstrated in the isomerization of 14. In this case, a tetrahydroindene cycloadduct $\mathbf{1 5}$ was formed in excellent yield (Scheme 5, eq. 2). Again, these reactions demonstrate that a range of fused bicyclic skeletons can be accessed by this tandem 1,2-indole migration/Nazarov cyclization reaction.

We were also intrigued about the mechanism that would follow an intermediate 7 (see Scheme 3) in which both mechanisms, the metalla-iso-Nazarov and the Nazarov mechanisms, are possible. So, we designed an experiment by using the biphenyl-substituted starting materials 16a-b (Scheme 5, eq. 3). After the initial 1,2migration of the indole moiety an intermediate $\mathbf{1 8}$ (analogous to $\mathbf{7}$ in Scheme 3) should be formed. This intermediate could evolve through an aura-iso-Nazarov mechanism (path $a$ in Scheme 3) or 
through an aura-Nazarov mechanism (path $b$ in Scheme 3). However, we only observed the formation of compounds $\mathbf{1 7} \mathbf{a}-\mathbf{b}$ indicating the preference of the Nazarov mechanism in this highly congested case.<smiles>[R]c1c(C(C)(C#Cc2ccsc2)C2CC2)c2ccccc2n1C</smiles>

12a: $\mathrm{R}=\mathrm{H}$

b: $\mathrm{R}=\mathrm{Me}$<smiles>Cn1cc(C(C)(C#CC2=CCCCC2)C2CC2)c2ccccc21</smiles>

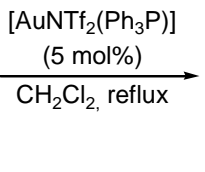

14<smiles>[R]c1ccc2[nH]cc(C(C)(C#Cc3ccccc3-c3ccccc3)C3CC3)c2c1</smiles>

$\left[\mathrm{AuNTf}{ }_{2}\left(\mathrm{Ph}_{3} \mathrm{P}\right)\right]$

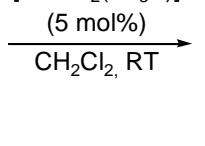<smiles>CC(C)c1ccc2[nH]cc(C3=Cc4c(-c5ccccc5)cccc4C3(C)C3CC3)c2c1</smiles><smiles>Cn1cc(C2=CC3=C(CCCC3)C2(C)C2CC2)c2ccccc21</smiles>

$15(88 \%)$

$$
\begin{aligned}
\text { 16a: } R^{1} & =\mathrm{Me}, \mathrm{R}^{2}=\mathrm{H} \\
\text { b: } R^{1} & =\mathrm{H}, \mathrm{R}^{2}=\mathrm{CO}_{2} \mathrm{Me}
\end{aligned}
$$
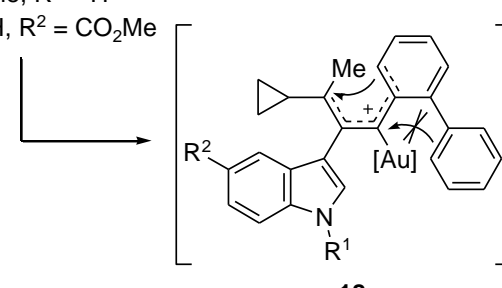

18

Scheme 5. Gold-catalyzed tandem 1,2-indole migration/Nazarov cyclization reactions of indole derivatives 12, 14 and $\mathbf{1 6}$.

Synthesis of 3-dienylindoles 20 by tandem 1,2-indole migration/1,2-C-H insertion reactions: Finally, we wondered if the proposed gold-carbene intermediate 7 (Scheme 3) could evolve trough new reaction pathways when the aura-iso-Nazarov and the aura-Nazarov cyclization were not possible. To this end, indole 19a that contains a 2,6-disubstitued phenyl group at the propargylic position and an alkyl group at terminal position of the triple bond, as well as indoles 19b-e, bearing only alkyl substituents at those positions, were tested under the standard conditions (Scheme 6 and Table 4). With all these substrates a new evolution of the intermediate gold-carbenoid complex 21 (analogous to 7 in Scheme 3 ) was observed consisting on a $1,2-\mathrm{C}-\mathrm{H}$ insertion reaction to finally furnish 3-dienylindole derivatives $\mathbf{2 0}$ as mixtures of geometric isomers. ${ }^{[31]}$ It should be noted that this kind of evolution of the gold-carbenoid intermediate could also be possible with indoles 1 possessing an alkyl group at the terminal position of the triple bond (see Table 2, entries 4-5, 7-10, and 14). However, in those cases the more favoured aura-iso-Nazarov operates to give the corresponding products $\mathbf{3}$ and we did not observe the formation of the alternative products $\mathbf{2 0}$.

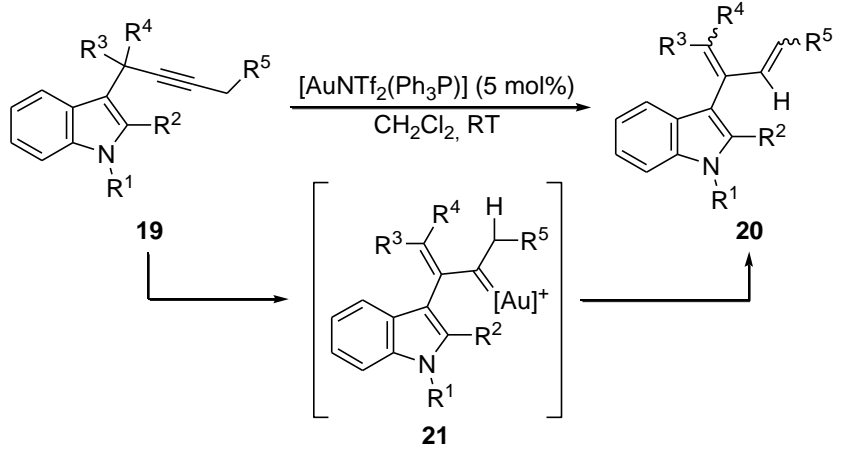

Scheme 6. Gold-catalyzed tandem 1,2-indole migration/1,2-C-H insertion reactions of indole derivatives 19.

Table 4. Synthesis of 3-(1,3-dien-2-yl)indoles 20 by gold-catalyzed tandem 1,2-indole migration/1,2-C-H insertion reactions of C-3-propargylated indole derivatives 19. ${ }^{\text {[a }}$

\begin{tabular}{lllllllll}
\hline Entry & 19 & $\mathrm{R}^{1}$ & $\mathrm{R}^{2}$ & $\mathrm{R}^{3}$ & $\mathrm{R}^{4}$ & $\mathrm{R}^{5}$ & $\mathbf{2 0}$ & $\begin{array}{l}\text { Yield } \\
{[\%]^{[\mathrm{b}]}}\end{array}$ \\
\hline 1 & $\mathbf{1 9 a}$ & $\mathrm{Me}$ & $\mathrm{H}$ & $\mathrm{Me}$ & $2,6-\mathrm{F}_{2} \mathrm{C}_{6} \mathrm{H}_{4}$ & $n \mathrm{nr}$ & $\mathbf{2 0 a}$ & 89 \\
2 & $\mathbf{1 9 b}$ & $\mathrm{Me}$ & $\mathrm{Ph}$ & $\mathrm{Me}$ & $c \mathrm{C}_{3} \mathrm{H}_{5}$ & $n \mathrm{Pr}$ & $\mathbf{2 0 b}$ & 85 \\
3 & $\mathbf{1 9 c}$ & $\mathrm{Me}$ & $\mathrm{Ph}$ & $c \mathrm{C}_{3} \mathrm{H}_{5}$ & $c \mathrm{C}_{3} \mathrm{H}_{5}$ & $n \mathrm{Pr}$ & $\mathbf{2 0 c}$ & 91 \\
4 & $\mathbf{1 9 d}$ & $\mathrm{Me}$ & $\mathrm{Ph}$ & $\mathrm{Me}$ & $\mathrm{Me}$ & $n \mathrm{Bu}$ & $\mathbf{2 0 d}$ & 64 \\
5 & $\mathbf{1 9 e}$ & $\mathrm{Me}$ & $\mathrm{Me}$ & $c \mathrm{C}_{3} \mathrm{H}_{5}$ & $c \mathrm{C}_{3} \mathrm{H}_{5}$ & $n \mathrm{Pr}$ & $\mathbf{2 0 e}$ & $56^{[\mathrm{c}]}$ \\
\hline
\end{tabular}

[a] Reactions stirred at RT till consumption of the starting material $(7-16 \mathrm{~h})$, as judged by GC-MS analysis. [b] Yield of isolated product based on the corresponding starting indole 19. [c] $36 \mathrm{~h}$ at reflux.

One-pot procedure for the synthesis of compounds $3,4,11$ and 20 from indoles and propargylic alcohols: Taking into account that all the starting indole-containing alkyne derivatives were synthesized from the corresponding propargylic alcohols by our reported Brønsted acid-catalyzed procedure, ${ }^{[32]}$ we wondered if it would be possible to access indene derivatives 3 (aura-iso-Nazarov products) or 4 (aura-Nazarov products) from readily available starting materials, such as alkynols $\mathbf{2 3}$, by using a concurrent tandem catalysis protocol. ${ }^{[33]}$ Thus, as shown in Table 5, the consecutive reaction of indoles 22 and propargylic alcohols 23 with PTSA (5 mol\%) and $\left[\mathrm{AuNTf}_{2}\left(\mathrm{Ph}_{3} \mathrm{P}\right)\right](5 \mathrm{~mol} \%)$ in $\mathrm{CH}_{2} \mathrm{Cl}_{2}$ at room temperature, led to the formation of 3-indenylindoles $\mathbf{3}$ or $\mathbf{4}$ in good yields. Notably, this one-pot procedure does not require any solvent change or removal of PTSA prior to the addition of the gold catalyst. ${ }^{[34]}$ By following this strategy the isolation of starting alkynes $\mathbf{1}$ or $\mathbf{2}$ is avoided, and the reaction can be performed from readily available propargylic alcohols and indoles in a straightforward manner. By using this one-pot protocol, some of the previously prepared 3 -indenylindoles $\mathbf{3}$ or $\mathbf{4}$ have been synthesized and in addition, two new derivatives $\mathbf{3}$ (compounds $\mathbf{3 y - z}$ in Table 5, entries 4 and 5) have been obtained.

Table 5. One-pot preparation of 3-indenylindoles 3 and 4 from indoles 22 and propargylic alcohols $\mathbf{2 3}{ }^{[a]}$ 


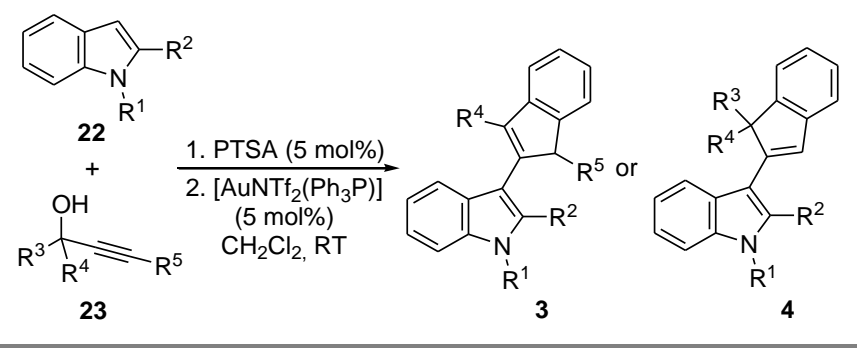

\begin{tabular}{|c|c|c|c|c|c|c|c|c|}
\hline \multicolumn{2}{|c|}{ Entry 22} & \multirow{2}{*}{$\begin{array}{l}\mathrm{R}^{1} \mathrm{R}^{2} \\
\mathrm{Me} \mathrm{H}\end{array}$} & \multirow{2}{*}{\begin{tabular}{|l}
23 \\
$23 a$
\end{tabular}} & \multirow{2}{*}{$\begin{array}{l}\mathrm{R}^{3} \\
\mathrm{iPr}\end{array}$} & \multirow{2}{*}{$\begin{array}{l}\mathrm{R}^{4} \\
\mathrm{Ph}\end{array}$} & \multirow{2}{*}{$\begin{array}{l}\mathrm{R}^{5} \\
\mathrm{Ph}\end{array}$} & \multirow{2}{*}{$\begin{array}{l}\text { Product } \\
\text { 3c }\end{array}$} & \multirow{2}{*}{$\begin{array}{l}\text { Yield } \\
{[\%]^{[b]}} \\
70\end{array}$} \\
\hline 1 & $22 a$ & & & & & & & \\
\hline 2 & $22 a$ & $\mathrm{Me} \mathrm{H}$ & $23 b$ & $c \mathrm{C}_{3} \mathrm{H}_{5}$ & $\mathrm{Ph}$ & $\mathrm{H}$ & $3 r$ & 70 \\
\hline 3 & $22 b$ & $\mathrm{H} \quad \mathrm{H}$ & $23 c$ & $\mathrm{Me}$ & $\mathrm{Ph}$ & $n \mathrm{Bu}$ & $3 g$ & $50^{[c]}$ \\
\hline 4 & $22 c$ & $\mathrm{Me}$ & 23d & $c \mathrm{C}_{3} \mathrm{H}_{5}$ & $\mathrm{Ph}$ & $\mathrm{Ph}$ & $3 y$ & 68 \\
\hline 5 & $22 d$ & $\mathrm{Me} \mathrm{Me}$ & $23 e$ & Et & $\mathrm{Ph}$ & $n \mathrm{Bu}$ & $3 z$ & 51 \\
\hline 6 & $22 a$ & $\mathrm{Me} \mathrm{H}$ & $23 f$ & $c \mathrm{C}_{3} \mathrm{H}_{5}$ & $\mathrm{Me}$ & $\mathrm{Ph}$ & $4 c$ & 69 \\
\hline 7 & $22 c$ & $\mathrm{H} \quad \mathrm{Me}$ & $23 f$ & $c \mathrm{C}_{3} \mathrm{H}_{5}$ & $\mathrm{Me}$ & $\mathrm{Ph}$ & $4 e$ & 72 \\
\hline 8 & 22d & $\mathrm{Me} \mathrm{Me}$ & $23 f$ & $c \mathrm{C}_{3} \mathrm{H}_{5}$ & $\mathrm{Me}$ & $\mathrm{Ph}$ & $4 h$ & 70 \\
\hline
\end{tabular}

[a] All reactions were conducted by stirring at RT an equimolecular mixture of indole 22 and alkynol 23 in the presence of the appropriate catalyst till consumption of the starting material as judged by GC-MS analysis (global reaction time: 2-24 h. See Supporting Information). [b] Yield of isolated product based on the corresponding starting indole 22. [c] After the addition of the gold catalyst, the mixture was stirred at reflux for $48 \mathrm{~h}$

As shown in Scheme 7, this method is also convenient for the synthesis of fused-bicyclic compounds such as $\mathbf{1 3 b}$ and dienyl derivatives such as $\mathbf{2 0 c}$ from easily available starting materials.<smiles>Cc1cc2ccccc2n1C</smiles>

$23 \mathrm{~g}$

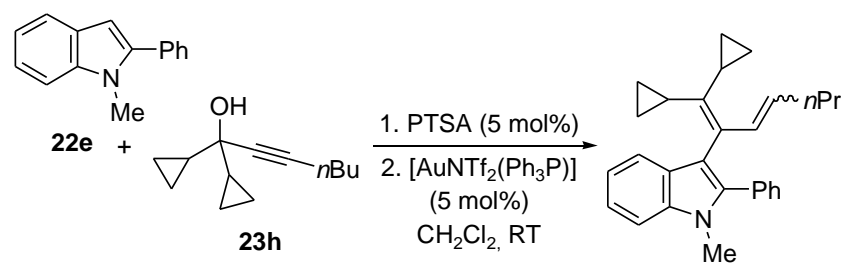

20c $(55 \%)$
Scheme 7. One-pot synthesis of compounds $\mathbf{1 3 b}$ and $\mathbf{2 0 c}$.

\section{Conclusion}

In conclusion, we have shown for the first time that a carboncentered nucleophile such as the indole nucleus is able to participate in gold-catalyzed 1,2-migration reactions of propargylic systems. The gold-carbenoid intermediates selectively undergo further cyclizations to give 3-(inden-2-yl)indoles. Depending on the substituents at the propargylic and terminal positions of the starting 3-propargylindole two different reaction pathways may operate, an iso-Nazarov or a Nazarov-type pentadienyl cyclization. In addition, DFT calculations reveal that after the initial indole attack on the activated alkyne, the alkylidenecyclopropane derivative obtained rearranges through a torqueselective electrocyclic ring opening to furnish a gold carbocation/carbenoid. The subsequent electrocyclic ring closures can be considered as gold variants of the Nazarov or iso-Nazarov reactions. Interestingly, we found that it is also possible to perform these reactions following a concurrent tandem catalysis protocol starting from readily available propargylic alcohols and indoles, thus avoiding the isolation of the $\mathrm{C} 3$-propargylindoles. Also, a new evolution of the gold-carbene intermediate through a $1,2-\mathrm{C}-\mathrm{H}$ insertion reaction to give 3-dienylindoles has been observed in those cases where the favoured Nazarov or iso-Nazarov reactions are not possible. Many of the 3-functionalized indole derivatives are novel compounds that combine two common drug scaffolds, the indole and the indene moieties, and therefore hold considerable potential as biologically active products thus justifying the further development of this powerful complexity-generating reaction.

\section{Experimental Section}

General: All reactions were carried out under nitrogen atmosphere in oven-dried glassware with magnetic stirring. $\mathrm{CH}_{2} \mathrm{Cl}_{2}$ was analytical grade, diethyl ether, ethyl acetate and hexane, were obtained from commercial suppliers and used without further purification. TLC was performed on aluminium-backed plates coated with silica gel 60 (230-240 mesh) with $\mathrm{F}_{254}$ indicator. The spots were visualized with UV light (254 nm) and/or staining with Ce/Mo reagent or phosphomolybdic acid solution and subsequent heating. ${ }^{1} \mathrm{H}$ and ${ }^{13} \mathrm{C}$ NMR spectra were recorded at 300 (or 400) and 75.4 (or 100.6) $\mathrm{MHz}$, respectively, and measured at room temperature or at $50{ }^{\circ} \mathrm{C}$ as specified. Chemical shifts in ${ }^{1} \mathrm{H}$ NMR spectra are reported in ppm using residual solvent peak as reference $\left(\mathrm{CHCl}_{3}: \delta 7.16\right)$. Data are reported as follows: chemical shift, multiplicity (s: singlet, br s: broad singlet, d: doublet, t: triplet, q: quartet, qt: quintuplet, m: multiplet, $\mathrm{dd}$ : double doublet, dt: double triplet, td: triple doublet, $\mathrm{ABq}$ : $\mathrm{AB}$ quartet), coupling constant $(J$ in $\mathrm{Hz})$ and integration. ${ }^{13} \mathrm{C}$ NMR spectra were recorded using broadband proton decoupling and chemical shifts are reported in ppm using residual solvent peaks as reference $\left(\mathrm{CDCl}_{3}: \delta 77.16\right)$. High resolution mass spectra (HRMS) were recorded on a Micromass Autospec spectrometer using EI at 70eV. Melting points were measured using open capillary rubes and are uncorrected. GC-MS and low resolution mass spectra (LRMS) measurements were recorded on a Agilent 6890N/5973 Network GC System, equipped with a HP-5MS column.

Typical procedure for the gold(I)-catalyzed tandem 1,2-indole migration/isoNazarov reactions of alkynes 1 and 10. Synthesis of 3-(3-Ethyl-1-phenyl-1 $H$-inden2-yl)-1-methyl-1 $\boldsymbol{H}$-indole (3a): To a solution of 3-(1,1-diethyl-3-phenyl-prop-2-ynyl)1-methyl-1H-indole (1a) $(175 \mathrm{mg}, 0.5 \mathrm{mmol})$ in analytical grade $\mathrm{CH}_{2} \mathrm{Cl}_{2}(1 \mathrm{~mL})$ was added $\left[\operatorname{AuNTf}_{2}\left(\mathrm{Ph}_{3} \mathrm{P}\right)\right](18.5 \mathrm{mg}, 0.025 \mathrm{mmol}, 5 \mathrm{~mol} \%)$ at room temperature under a nitrogen atmosphere. The resulting mixture was stirred at room temperature for $1 \mathrm{~h}$ (complete conversion was monitored by GC-MS and/or TLC). After removing of the solvent, the crude was purified by column chromatography on silica gel using hexane:diethyl ether (7:1) as eluent to afford compound 3a (138 $\mathrm{mg}, 79 \%)$ as a white solid; m.p. $134-136{ }^{\circ} \mathrm{C} ; R_{\mathrm{f}}=0.35$ (hexane:diethyl ether, 5:1); ${ }^{1} \mathrm{H}$ NMR $(300 \mathrm{MHz}$, $\left.\mathrm{CDCl}_{3}, 25^{\circ} \mathrm{C}\right): \delta=1.41\left(\mathrm{dt}, J=7.5 \mathrm{~Hz}, 3 \mathrm{H} ; \mathrm{CH}_{3}\right), 2.88\left(\mathrm{q}, J=7.5 \mathrm{~Hz}, 2 \mathrm{H} ; \mathrm{CH}_{2}\right), 3.67(\mathrm{~s}$, $\left.3 \mathrm{H} ; \mathrm{NCH}_{3}\right), 5.10(\mathrm{~s}, 1 \mathrm{H} ; \mathrm{CHPh}), 6.72(\mathrm{~s}, 1 \mathrm{H} ; \mathrm{NCH}), 7.05-7.33(\mathrm{~m}, 10 \mathrm{H} ; \mathrm{ArH}), 7.43$ (td, $J=7.5,1.2 \mathrm{~Hz}, 1 \mathrm{H} ; \operatorname{Ar} H), 7.56(\mathrm{~d}, J=7.5 \mathrm{~Hz}, 1 \mathrm{H} ; \operatorname{Ar} H), 7.77 \mathrm{ppm}(\mathrm{d}, J=7.5 \mathrm{~Hz}, 1 \mathrm{H}$; $\mathrm{Ar} H) ;{ }^{13} \mathrm{C}$ NMR $\left(75.4 \mathrm{MHz}, \mathrm{CDCl}_{3}, 25{ }^{\circ} \mathrm{C}\right): \delta=14.1,20.0,32.8,58.9,109.4,111.1$, $119.2,119.4,120.5,121.6,123.9,124.7,126.5,126.7,127.6,127.8,128.3,128.4,136.8$ 138.9, 140.6, 141.1, 145.4, 148.9 ppm; LRMS(EI): $\mathrm{m} / \mathrm{z}(\%): 349\left(\mathrm{M}^{+}, 8\right), 320$ (100); HRMS (EI) calcd for $\mathrm{C}_{26} \mathrm{H}_{23} \mathrm{~N}$ : 349.1830; found: 349.1830; elemental analysis calcd (\%) for $\mathrm{C}_{26} \mathrm{H}_{23} \mathrm{~N}$ : C 89.36, H 6.63, N 4.01; found: C 89.15, H 6.65, N 3.98 .

Typical procedure for the gold(I)-catalyzed tandem 1,2-indole migration/Nazarov reactions of alkynes $2,12,14$, and 16. Synthesis of 3-(1,1-Diethyl-1 $H$-inden-2-yl)-1methyl-1H-indole (4a): To a solution of 3-(1,1-diethyl-3-phenyl-prop-2-ynyl)-1methyl-1H-indole (2a) $(151 \mathrm{mg}, 0.5 \mathrm{mmol})$ in analytical grade $\mathrm{CH}_{2} \mathrm{Cl}_{2}(1 \mathrm{~mL})$ was added $\left[\mathrm{AuNTf}_{2}\left(\mathrm{Ph}_{3} \mathrm{P}\right)\right](18.5 \mathrm{mg}, 0.025 \mathrm{mmol}, 5 \mathrm{~mol} \%)$ at room temperature under a nitrogen atmosphere. The resulting mixture was stirred at reflux for $24 \mathrm{~h}$ (complete conversion monitored by GC-MS and/or TLC). After removing of the solvent, the crude was purified by column chromatography on silica gel using hexane:diethyl ether $(10: 1)$ as eluent to afford $4 \mathbf{a}(102 \mathrm{mg}, 68 \%)$ as a white solid; m.p. $133-135{ }^{\circ} \mathrm{C} ; R_{\mathrm{f}}=$ 0.33 (hexane:diethyl ether, 9:1); ${ }^{1} \mathrm{H}$ NMR $\left(300 \mathrm{MHz}, \mathrm{CDCl}_{3}, 25^{\circ} \mathrm{C}\right): \delta=0.37$ (t, $J=7.3$ $\left.\mathrm{Hz}, 6 \mathrm{H} ; 2 \times \mathrm{CH}_{3} \mathrm{CH}_{2}\right), 2.05\left(\mathrm{q}, J=7.3 \mathrm{~Hz}, 2 \mathrm{H} ; \mathrm{CH}_{3} \mathrm{CH}_{2}\right), 2.06(\mathrm{q}, J=7.3 \mathrm{~Hz}, 2 \mathrm{H}$; $\left.\mathrm{CH}_{3} \mathrm{CH}_{2}\right), 3.86\left(\mathrm{~s}, 3 \mathrm{H} ; \mathrm{NCH}_{3}\right), 7.14-7.41(\mathrm{~m}, 9 \mathrm{H} ;=\mathrm{CH}$ and $\mathrm{ArH}), 8.09 \mathrm{ppm}(\mathrm{dd}, J=4.5$, $4.0 \mathrm{~Hz}, 1 \mathrm{H} ; \mathrm{Ar} H) ;{ }^{13} \mathrm{C} \mathrm{NMR}\left(75.4 \mathrm{MHz}, \mathrm{CDCl}_{3}, 25^{\circ} \mathrm{C}\right): \delta=8.4,32.0,31.2,60.8,109.5$, $111.2,119.9,120.2,121.0,121.3,122.3,124.0,126.2,126.4,126.6,127.4,137.2,145.7$ 145.9, 149.9 ppm; LRMS (EI): $\mathrm{m} / z(\%): 301\left(\mathrm{M}^{+}, 94\right), 286(10), 272(100), 256(33)$, 241 (10). HRMS (EI) calcd for $\mathrm{C}_{22} \mathrm{H}_{23} \mathrm{~N}$ : 301.1830; found: 301.1829 . 
Typical procedure for the gold(I)-catalyzed tandem 1,2-indole migration/1,2-C-H insertion reactions of alkynes 19. Synthesis of 3-(1,1-Dicyclopropylhepta-1,3-dien2-yl)-1-methyl-2-phenyl-1 $\boldsymbol{H}$-indole (20c): To a solution of 3-(1,1-dicyclopropyl-hept2-ynyl)-1-methyl-2-phenyl-1H-indole (19c) $(191 \mathrm{mg}, 0.5 \mathrm{mmol})$ in analytical grade $\mathrm{CH}_{2} \mathrm{Cl}_{2}(1 \mathrm{~mL})$ was added $\left[\mathrm{AuNTf}_{2}\left(\mathrm{Ph}_{3} \mathrm{P}\right)\right](18.5 \mathrm{mg}, 0.025 \mathrm{mmol}, 5 \mathrm{~mol} \%)$ at room temperature under a nitrogen atmosphere. The resulting mixture was stirred at room temperature for $16 \mathrm{~h}$ (complete conversion monitored by GC-MS and/or TLC). After removing of the solvent, the crude was purified by column chromatography on silica ge using hexane:diethyl ether (50:1) as eluent to afford 20c (174 mg, 91\%) as a colourless oil (mixture of isomers $E: Z, \sim 2: 1) ; R_{\mathrm{f}}=0.15$ (hexane); ${ }^{1} \mathrm{H}$ NMR $\left(300 \mathrm{MHz}, \mathrm{CDCl}_{3}, 25\right.$ $\left.{ }^{\circ} \mathrm{C}\right): \delta=0.08-1.33(\mathrm{~m}, 12 \mathrm{H}$ maj $+12 \mathrm{H} \mathrm{min}), 0.75\left(\mathrm{t}, J=7.4 \mathrm{~Hz}, 3 \mathrm{H} \mathrm{min} ; \mathrm{CH}_{3}\left(\mathrm{CH}_{2}\right)_{2}\right)$, $0.84\left(\mathrm{t}, J=7.4 \mathrm{~Hz}, 3 \mathrm{H}\right.$ maj; $\left.\mathrm{CH}_{3}\left(\mathrm{CH}_{2}\right)_{2}\right), 1.62-1.74$ (m, $\left.1 \mathrm{H} \mathrm{min} ; \mathrm{CH}_{3} \mathrm{CH}_{2} \mathrm{CH} H\right)$, 1.78-1.95 (m, $1 \mathrm{H}$ min; $\mathrm{CH}_{3} \mathrm{CH}_{2} \mathrm{CHH}$ ), 1.99-2.11 (m, 2H maj; $\mathrm{CH}_{3} \mathrm{CH}_{2} \mathrm{CH}_{2}$ ), 3.74 (s $3 \mathrm{H}$ min; $\left.\mathrm{NCH}_{3}\right), 3.78\left(\mathrm{~s}, 3 \mathrm{H}\right.$ maj; $\left.\mathrm{NCH}_{3}\right), 5.22-5.34(\mathrm{~m}, 1 \mathrm{H}$ maj $+1 \mathrm{H} \mathrm{min}$ $\left.\mathrm{CH}_{3}\left(\mathrm{CH}_{2}\right)_{2} \mathrm{CH}\right), 6.13(\mathrm{~d}, J=11.5 \mathrm{~Hz}, 1 \mathrm{H} \mathrm{min} ;=\mathrm{CCH}), 6.94(\mathrm{dt}, J=15.4,1.3 \mathrm{~Hz}, 1 \mathrm{H}$ maj; $=\mathrm{CCH}), 7.09-7.18(\mathrm{~m}, 1 \mathrm{H} \mathrm{maj}+1 \mathrm{H} \mathrm{min} ; \mathrm{ArH}), 7.23-7.61 \mathrm{ppm}(\mathrm{m}, 8 \mathrm{H} \mathrm{maj}+8 \mathrm{H}$ $\min ; \operatorname{Ar} H) ;{ }^{13} \mathrm{C}$ NMR $\left(75.4 \mathrm{MHz}, \mathrm{CDCl}_{3}, 25{ }^{\circ} \mathrm{C}\right.$ ): $\delta=5.5$ (maj), 5.8 (min), 6.0 (min), 6.08 (min), 6.13 (maj), 6.4 (maj), 11.5 (maj), 12.9 (min), 13.8 (maj), 14.2 (min), 15.3 (min), 16.2 (maj), 22.7 (min), 22.8 (maj), 30.9 (min), 31.4 (min), 31.5 (maj), 35.4 (maj) 109.27 (maj), 109. 31 (min), 114.2 (maj), 116.0 (min), 119.27 (maj), 119.33 (min) 120.6 (min), 120.8 (maj), 121.5 (maj), 121.6 (min), 127.37 (maj), 127.40 (min), 127.7 (min), 127.9 (maj), 128.0 (min), 128.3 (maj), 130.0 (maj), 130.1 (maj), 130.3 (min), 130.5 (maj), 130.7 (min), 130.8 (min), 131.5 (maj), 132.7 (maj), 132.8 (min), 137.5 (min), 137.7 (maj), 137.9 (min), 138.8 (maj), 139.3 (maj), 140.9 (min) ppm; LRMS (EI): $m / z(\%): 381\left(\mathbf{M}^{+}, 15\right), 338(100), 207$ (94)

General procedure for the one-pot protocol from indoles 22 and alkynols 23: To solution of the appropriate indole $22(0.5 \mathrm{mmol})$ and alkynol $23(0.5 \mathrm{mmol})$ in analytical grade $\mathrm{CH}_{2} \mathrm{Cl}_{2}(1 \mathrm{~mL})$, PTSA $(4.8 \mathrm{mg}, 0.025 \mathrm{mmol}, 5 \mathrm{~mol} \%)$ was added at room temperature under a nitrogen atmosphere. The resulting mixture was stirred at room temperature until complete conversion (monitored by GC-MS and/or TLC). Then $\left[\operatorname{AuNTf}_{2}\left(\mathrm{Ph}_{3} \mathrm{P}\right)\right](18.5 \mathrm{mg}, 0.025 \mathrm{mmol}, 5 \mathrm{~mol} \%)$ was added and the resulting slurry was stirred at room temperature until complete conversion (monitored by GC-MS and/or TLC). After removing of the solvent, the crude was purified by column chromatography on silica gel or neutral aluminum oxide using the appropriate mixture of hexane and diethyl ether or ethyl acetate as eluent to afford compounds $3, \mathbf{4 , 1 3}$ or 20 in the yields reported in Table 5 and Scheme 7.

\section{Acknowledgements}

We grateful thank MEC/FEDER (CTQ2007-61436/BQU) and Junta de Castilla y León (BU021A09) for financial support. We are also grateful to MEC (FPU predoctora fellowship to D.M., "Young Foreign Researchers" contract (SB2006-0215) to M.G., "Ramón y Cajal" contract to M.A.F.-R., and "Juan de la Cierva" contract to P.G.-G.) and Fundación Ramón Areces (predoctoral fellowship to A.G.P.). We are indebted to the Centro de Supercomputación de Galicia (CESGA) for generous allocation of computational resources.

[1] For recent reviews, see: a) A. Fürstner, P. W. Davies, Angew. Chem. 2007, 119 3478-3519; Angew. Chem. Int. Ed. 2007, 46, 3410-3449. b) E. Jiménez-Núñez, A. M. Echavarren, Chem. Rev. 2008, 108, 3326-3350. c) V. Michelet, P. Y Toullec, J.-P. Genêt, Angew. Chem. 2008, 120, 4338-4386; Angew. Chem. Int Ed. 2008, 47, 4268-4315. d) N. D. Shapiro, F. D. Toste, Synlett 2010, 675-691. e) S. Wang, G. Zhang, L. Zhang, Synlett 2010, 692-706.

[2] a) N. Marion, S. P. Nolan, Angew. Chem. 2007, 119, 2806-2809; Angew. Chem. Int. Ed. 2007, 46, 2750-2752. b) J. Marco-Contelles, E. Soriano, Chem. Eur. J. 2007, 13, 1350-1357.

[3] See, for instance: a) M. J. Johansson, D. J. Gorin, S. T. Staben, F. D. Toste, J. Am. Chem. Soc. 2005, 127, 18002-18003. b) C. H. M. Amijs, V. López-Carrillo, A. M. Echavarren, Org. Lett. 2007, 9, 4021-4024. c) G. Li, G. Zhang, L. Zhang, J. Am. Chem. Soc. 2008, 130, 3740-3741. d) P. W. Davies, S. J.-C. Albrecht, Chem. Commun. 2008, 238-240. e) E. Soriano, J. Marco-Contelles, Chem. Eur. J. 2008, 14, 6771-6779. f) I. D. G. Watson, S. Ritter, F. D. Toste, J. Am. Chem. Soc. 2009, 131, 2056-2057. g) M. Uemura, I. D. G. Watson, M. Katsukawa, F. D. Toste, J. Am. Chem. Soc. 2009, 131, 3464-3465.

[4] a) L. Peng, X. Zhang, S. Zhang, J. Wang, J. Org. Chem. 2007, 72, 1192-1197. b) X. Zhao, Z. Zhong, L. Penga, W. Zhang, J. Wang, Chem. Commun. 2009, 2535-2537.

[5] R. Sanz, D. Miguel, F. Rodríguez, Angew. Chem. 2008, 120, 7464-7467; Angew. Chem. Int. Ed. 2008, 47, 7354-7357.

[6] S. Lakhdar, M. Westermaier, F. Terrier, R. Goumont, T. Boubaker, A. R. Ofial, H. Mayr, J. Org. Chem. 2006, 71, 9088-9095.

[7] See, for instance: a) L. Zhang, J. Am. Chem. Soc. 2005, 127, 16804-16805. b) C. Ferrer, A. M. Echavarren, Angew. Chem. 2006, 118, 1123-1127; Angew. Chem.
Int. Ed. 2006, 45, 1105-1109. c) C. Liu, R. A. Widenhoefer, Org. Lett. 2007, 9 , 1935-1938. d) C. Ferrer, C. H. M. Amijs, A. M. Echavarren, Chem. Eur. J. 2007, 13, 1358-1373. e) D. B. England, A. Padwa, Org. Lett. 2008, 10, 3631-3634. f) G. Zhang, X. Huang, G. Li, L. Zhang, J. Am. Chem. Soc. 2008 130, 1814-1815. g) Lu, X. Du, X. Jia, Y. Liu, Adv. Synth. Catal. 2009, 351, 1517-1522. h) J. Barluenga, A. Fernández, F. Rodríguez, F. J. Fañanás, J. Organomet. Chem. 2009, 694, 546-550. i) J. Barluenga, A. Fernández, F. Rodríguez, F. J. Fañanás, Chem. Eur. J. 2009, 15, 8121-8123. j) Y Y. Liu, W. Xu, X. Wang, Org. Lett. 2010, 12, 1448-1451. k) G. Li, Y. Liu, J. Org. Chem. 2010, 75, 3526-3528.

[8] a) R. Sanz, D. Miguel, J. M. Álvarez-Gutiérrez, F. Rodríguez, Synlett 2008 975-978. b) R. Sanz, M. Gohain, D. Miguel, A. Martínez, F. Rodríguez, Synlet 2009, 1985-1989. See, also: c) R. Sanz, A. Martínez, J. M. Álvarez-Gutiérrez, F. Rodríguez, Eur. J. Org. Chem. 2006, 1383-1386. d) R. Sanz, A. Martínez, D. Miguel, J. M. Álvarez-Gutiérrez, F. Rodríguez, Adv. Synth. Catal. 2006, 348 1841-1845. e) R. Sanz, D. Miguel, A. Martínez, J. M. Álvarez-Gutiérrez, F. Rodríguez, Org. Lett. 2007, 9, 727-730. f) R. Sanz, D. Miguel, A. Martínez, J. M. Álvarez-Gutiérrez, F. Rodríguez, Org. Lett. 2007, 9, 2027-2030.

[9] $\left[\operatorname{AuNTf}_{2}\left(\mathrm{Ph}_{3} \mathrm{P}\right)\right],\left[\mathrm{AuNTf}_{2}(\mathrm{SPhos})\right]$ (SPhos = 2-dicyclohexylphosphino-2',6'dimethoxybiphenyl), as well as $\left[\mathrm{AuSbF}_{6}\left(\mathrm{Ph}_{3} \mathrm{P}\right)\right]$ generated in situ from $\left[\mathrm{AuCl}\left(\mathrm{Ph}_{3} \mathrm{P}\right)\right]$ and $\mathrm{AgSbF}_{6}$, resulted to be useful catalysts for this transformation (see Supporting Information).

[10] For bis(trifluoromethanesulfonyl)imidate-based gold catalysts, see: N. Mézailles, L. Ricard, F. Gagosz, Org. Lett. 2005, 7, 4133-4136.

[11] CCDC $689754(\mathbf{3 c}), 689755$ (3e), 689757 (4a), 689756 (4b), and 772902 (13b) contain the supplementary crystallographic data for this paper. These data can be obtained free of charge from The Cambridge Crystallographic Data Centre via www.ccdc.cam.ac.uk/data_request/cif.

[12] For examples of formal iso-Nazarov reactions catalyzed by gold, see: a) G.-Y Lin, C.-W. Li, S.-H. Hung, R.-S. Liu, Org. Lett. 2008, 10, 5059-5062. b) C.-C. Lin, T.-M. Teng, C.-C. Tsai, H.-Y. Liao, R.-S. Liu, J. Am. Chem. Soc. 2008, 130 16417-16423. c) S. Bhunia, R.-S. Liu, J. Am. Chem. Soc. 2008, 130, 16488-16489.

[13] For examples of formal Nazarov reactions catalyzed by noble metals, see: a) G Lemière, V. Gandon, K. Coriou, T. Fukuyama, A.-L. Dhimane, L. Fensterbank, M. Malacria, Org. Lett. 2007, 9, 2207-2209. b) S. G. Sethofer, S. T. Staben, O. Y. Hung, F. D. Toste, Org. Lett. 2008, 10, 4315-4318. c) G. Lemière, V. Gandon, K. Cariou, A. Hours, T. Fukuyama, A.-L. Dhimane, L. Fensterbank, M. Malacria, J. Am. Chem. Soc. 2009, 131, 2993-3006. d) E. Jiménez-Núñez, M Raducan, T. Lauterbach, K. Molawi, C. R. Solorio, A. M. Echavarren, Angew. Chem. 2009, 121, 6268-6271; Angew. Chem. Int. Ed. 2009, 48, 6152-6155. e) P. Cordier, C. Aubert, M. Malacria, E. Lacòte, V. Gandon, Angew. Chem. 2009, 121, 8913-8916; Angew. Chem. Int. Ed. 2009, 48, 8757-8760.

[14] Z.-B. Zhu, M. Shi, Chem. Eur. J. 2008, 14, 10219-10222

[15] For our previous computational studies on the cyclization of pentadienyl cations, see: a) A. R. de Lera, J. García-Rey, D. Hrovat, B. Iglesias, S. López, Tetrahedron Lett. 1997, 38, 7425-7428. b) B. Iglesias, A. R. de Lera, J. Rodríguez-Otero, S. López, Chem. Eur. J. 2000, 6, 4021-4033. c) O. Nieto-Faza C. Silva-López, R. Álvarez, A. R. de Lera, Chem. Eur. J. 2004, 10, 4324-4333. d) O. Nieto-Faza, C. Silva-López, R. Alvarez, A. R. de Lera, Chem. Eur. J. 2009, 15, 1944-1956. For theoretical studies of the cyclization of a pentadienylcation with a vinylgold, see: e) O. Nieto-Faza, C. Silva-López, R. Álvarez, A. R. de Lera, J. Am. Chem. Soc. 2006, 128, 2434-2437. See also: f) G. Lemière, V. Gandon, K. Cariou, T. Fukuyama, A.-L. Dhimane, L. Fensterbank, M. Malacria, Org. Lett. 2007, 9, 2207-2209. g) F.-Q. Shi, X. Li, Y. Xia, L. Zhang, Z.-X. Yu, J. Am. Chem. Soc. 2007, 129, 15503-15512.

[16] a) A. D. Becke, J. Chem. Phys. 1993, 98, 5648-5652. b) C. Lee, W. Yang, R. G. Parr, Phys. Rev. B 1988, 37, 785. c) B. Miehlich, A. Savin, H. Stoll, H. Preuss, Chem. Phys. Lett. 1989, 157, 200-206.

[17] a) Y. Zhao, D. G. Truhlar, Acc. Chem. Res. 2008, 41, 157-167. b) Y. Zhao, D. G. Truhlar, Theor. Chem. Acc. 2008, 120, 215-241.

[18] R. Dithfield, W. J. Hehre, J. A. Pople, J. Chem. Phys. 1971, 54, 724-729.

[19] P. J. Hay, W. R. Wadt, J. Chem. Phys. 1985, 82, 270-283.

[20] a) J. Tomasi, M. Persico, Chem. Rev. 1994, 94, 2027-2094. b) J. Tomasi, B. Mennucci, R. Cammi, Chem. Rev. 2005, 105, 2999-3094.

[21] Gaussian 09, Revision A.1, M. J. Frisch, G. W. Trucks, H. B. Schlegel, G. E. Scuseria, M. A. Robb, J. R. Cheeseman, G. Scalmani, V. Barone, B. Mennucci, G. A. Petersson, H. Nakatsuji, M. Caricato, X. Li, H. P. Hratchian, A. F. Izmaylov, J. Bloino, G. Zheng, J. L. Sonnenberg, M. Hada, M. Ehara, K. Toyota, R. Fukuda, J. Hasegawa, M. Ishida, T. Nakajima, Y. Honda, O. Kitao, H. Nakai, T. Vreven, J. A. Montgomery, Jr., J. E. Peralta, F. Ogliaro, M. Bearpark, J. J. 
Heyd, E. Brothers, K. N. Kudin, V. N. Staroverov, R. Kobayashi, J. Normand, K. Raghavachari, A. Rendell, J. C. Burant, S. S. Iyengar, J. Tomasi, M. Cossi, N. Rega, J. M. Millam, M. Klene, J. E. Knox, J. B. Cross, V. Bakken, C. Adamo, J. Jaramillo, R. Gomperts, R. E. Stratmann, O. Yazyev, A. J. Austin, R. Cammi, C Pomelli, J. W. Ochterski, R. L. Martin, K. Morokuma, V. G. Zakrzewski, G. A Voth, P. Salvador, J. J. Dannenberg, S. Dapprich, A. D. Daniels, Ö. Farkas, J. B. Foresman, J. V. Ortiz, J. Cioslowski, and D. J. Fox, Gaussian, Inc., Wallingford CT, 2009.

[22] The syn/anti conformations about the $\mathrm{C} 3-\mathrm{C} 1$ ' bond were also considered (see Supporting Information), but their effect on activation energies and product outcome was negligible. See Supporting Information for a complete stereochemical depiction of the reaction course and the computational analysis of the alternative pathways.

[23] Strikingly, this bond reaches $1.79 \AA$ in the stereoisomer that originates from the syn coordination of gold (see Supporting Information) in an almost barrierless process.

[24] There are authoritative reports in the literature that advocate for a careful use of the term carbene in gold-catalyzed mechanisms and describe these structures a resulting from a $\pi$-Lewis activation by gold that makes the adjacent carbon more electrophilic, or even a carbocation: a) G. Seidel, R. Mynott, A. Fürstner, Angew. Chem. 2009, 121, 2548-2551; Angew. Chem. Int. Ed. 2009, 48, 2510-2513. b) S. Flügge, A. Anoop, R. Goddard, W. Thiel, A. Fürstner, Chem. Eur. J. 2009, 15 8558-8565. c) A. Fürstner, L. Morency, Angew. Chem. 2008, 120, 5108-5111; Angew. Chem. Int. Ed. 2008, 47, 5030-5033. The nature of the substituents and the ancillary ligand determine the varying degrees of $\sigma$ and $\pi$ bonding and the position of the gold species on a continuum from gold-stabilized singlet carbene to gold-stabilized carbocation. See: d) D. Benitez, N. D. Shapiro, E. Tkatchouk, Y. Wang, W. A. Goddard, F. D. Toste, Nat. Chem. 2009, 1, 482-486.

[25] Transition states tsVa and tsVIa are another example of a two-step nointermediate process using the B3LYP functional. a) D. A. Singleton, C. Hang, M. J. Szymanski, M. P. Meyer, A. G. Leach, K. T. Kuwata, J. S. Chen, A. Greer C. S. Foote, K. N. Houk J. Am. Chem. Soc. 2003, 125, 1319-1328. b) C. SilvaLópez, O. Nieto-Faza, R. Alvarez, A. R. de Lera, J. Org. Chem. 2006, 71 , $4497-4501$. We conducted a relaxed two-dimensional scan ${ }^{[26]}$ starting from Va over the $\mathrm{C} 3-\mathrm{C} 2$ ' and $\mathrm{C} 3-\mathrm{C} 1$ ' coordinates, corresponding to the bond formation and bond cleavage involved in the indole migration. Figure 1 of the Supporting Information depicts the resulting potential energy surface for the transformation of Va into VIIa in a 3D plot. Although the study discards a concerted transformation, the stepwise process is clearly of low energy (see Supporting Information)

[26] C. González, H. B. Schlegel, J. Chem. Phys. 1989, 90, 2154-2161.

[27] P. v. R. Schleyer, C. Maerker, A. Dransfeld, H. Jiao, N. J. R. v. E. Hommes, J Am. Chem. Soc. 1996, 118, 6317-6318.

[28] An aura-Nazarov pathway similar to that of VIIa would involve the termina phenyl group originating from the alternative structure with syn coordination of the gold catalyst to the indole ring. The Supporting Information includes the syn coordination manifold, which is non-competitive with the one shown in Figure 1

[29] Prepared from indole $\mathbf{1} \mathbf{r}$ by lithiation with $n \mathrm{BuLi}$ in THF and further treatmen with the corresponding electrophile (diphenyl disulfide and ethyl chloroformate) See the Supporting Information.

[30] For some selected examples of intramolecular hydroalkoxylation reactions of alkyne derivatives catalyzed by $\pi$-acid metallic species, see: a) S. Antoniotti, E. Genin, V. Michelet, J. -P Genêt, J. Am. Chem. Soc. 2005, 127, 9976-9977. b) J. Barluenga, A. Diéguez, A. Fernández, F. Rodríguez, F. J. Fañanás, Angew. Chem. 2006, 118, 2145-2147; Angew. Chem. Int. Ed. 2006, 45, 2091-2093. c) V. Belting, N. Krause, Org. Lett. 2006, 8, 4489-4492. d) B. Liu, J. K. De Brabander, Org. Lett. 2006, 8, 4907-4910. e) A. Diéguez-Vázquez, C. C. Tzschucke, W. Y. Lam, S. V. Ley, Angew. Chem. 2008, 120, 216-219; Angew. Chem. Int. Ed. 2008, 47, 209-212. f) J. Barluenga, A. Fernández, A. Satrústegui, A. Diéguez, F. Rodríguez, F. J. Fañanás, Chem. Eur. J. 2008, 14, 4153-4156. g) J. Barluenga, A. Mendoza, F. Rodríguez, F. J. Fañanás, Chem. Eur. J. 2008, 14 10892-10895. h) J. Barluenga, A. Mendoza, F. Rodríguez, F. J. Fañanás, Angew. Chem. 2009, 121, 1672-1675; Angew. Chem. Int. Ed. 2009, 48, 1644-1647. i) F. J. Fañanás, A. Fernández, D. Çevic, F. Rodríguez, J. Org. Chem. 2009, 74 932-934. j) J. Barluenga, A. Fernández, A. Diéguez, F. Rodríguez, F. J. Fañanás, Chem. Eur. J. 2009, 15, 11660-11667.

[31] G. Li, G. Zhang, L. Zhang, J. Am. Chem. Soc. 2008, 130, 3740-3741.

[32] R. Sanz, D. Miguel, A. Martínez, M. Gohain, P. García-García, M. A Fernández-Rodríguez, F. Rodríguez, submitted for publication. See, also ref [8a] and [8b]

[33] For excellent accounts on concurrent tandem catalysis, see: a) J.-C. Wasilke, S. J. Obrey, R. T. Baker, G. C. Bazan, Chem. Rev. 2005, 105, 1001-1020. b) A. M. Walji, D. W. C. McMillan, Synlett 2007, 1477-1489. For some examples of concurrent tandem Brønsted acid-/metal-catalysis, see: c) R. Sanz, A. Martínez, J. M. Álvarez-Gutiérrez, F. Rodríguez, Synthesis 2007, 3252-3256. d) J. Barluenga, A. Mendoza, F. Rodríguez, F. J. Fañanás, Angew. Chem. 2008, 120, 7152-7155; Angew. Chem. Int. Ed. 2008, 47, 7044-7047.

[34] No more than 1 equiv of starting alkynol should be used for the alkylation step as we have observed that an excess of the propargylic alcohol has a deleterious effect on the gold-catalysis.

Received: ((will be filled in by the editorial staff))

Revised: ((will be filled in by the editorial staff)) Published online: ((will be filled in by the editorial staff)) 
Indole

migrations

Roberto Sanz,* Delia Miguel, Mukut Gohain, Patricia GarcíaGarcía, Manuel A. FernándezRodríguez, Adán González-Pérez, Olalla Nieto-Faza, Ángel R. de Lera, * Félix Rodríguez*............ Page - Page

Synthesis of Diverse Indolecontaining Scaffolds by Gold(I)Catalyzed Tandem Reactions of 3-Propargylindoles Initiated by 1,2-Indole Migrations: Scope and Computational Studies
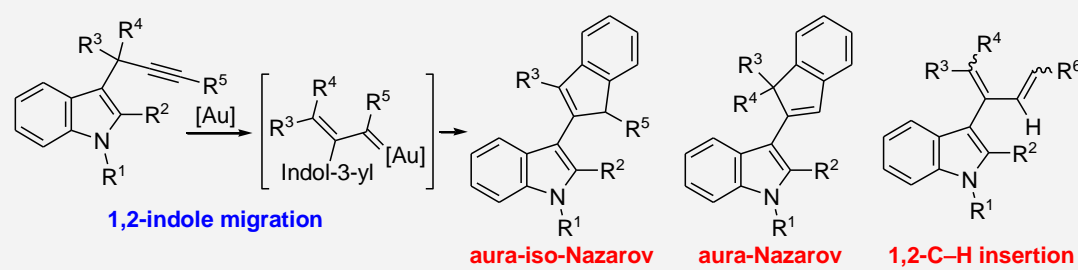

$\mathrm{R}^{4}=\mathrm{Ar}$

aura-Nazarov

1,2-C-H insertion $R^{5}=A r ; R^{3}, R^{4} \neq A r \quad R^{3}, R^{4}, R^{5} \neq A r$

3-Propargylindoles are able to participate in 1,2-migrations under gold-catalysis. Computational or aura-Nazarov cyclizations, whereas 3-(1,3-dien-2-yl)indoles are generated when none of these pathways are accessible. methods support a gold-carbenoid species as intermediate that undergoes different transformations depending on the substituents at the propargylic and terminal positions. 3-(Inden-2-yl)indoles could be accessed through aura-iso-Nazarov 